\title{
Continuous, Array-Based Estimates of Atlantic Ocean Heat Transport at $26.5^{\circ} \mathrm{N}$
}

\author{
W. E. Johns, ${ }^{*}$ M. O. Baringer, ${ }^{+}$L. M. Beal, ${ }^{*}$ S. A. Cunningham,\# T. KAnZOW, ${ }^{\#}$ H. L. Bryden,

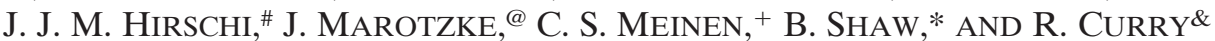 \\ * Division of Meteorology and Physical Oceanography, Rosenstiel School of Marine and Atmospheric Science, \\ University of Miami, Miami, Florida \\ ${ }^{+}$Physical Oceanography Division, NOAA/Atlantic Oceanographic and Meteorological Laboratory, Miami, Florida \\ \# Ocean Observing and Climate Research Group, National Oceanography Centre, Southampton, Southampton, United Kingdom \\ @ Max Planck Institute for Meteorology, Hamburg, Germany \\ ${ }^{\&}$ Woods Hole Oceanographic Institution, Woods Hole, Massachusetts
}

(Manuscript received 12 August 2010, in final form 1 December 2010)

\begin{abstract}
Continuous estimates of the oceanic meridional heat transport in the Atlantic are derived from the Rapid Climate Change-Meridional Overturning Circulation (MOC) and Heatflux Array (RAPID-MOCHA) observing system deployed along $26.5^{\circ} \mathrm{N}$, for the period from April 2004 to October 2007. The basinwide meridional heat transport (MHT) is derived by combining temperature transports (relative to a common reference) from 1 ) the Gulf Stream in the Straits of Florida; 2) the western boundary region offshore of Abaco, Bahamas; 3) the Ekman layer [derived from Quick Scatterometer (QuikSCAT) wind stresses]; and 4) the interior ocean monitored by "endpoint" dynamic height moorings. The interior eddy heat transport arising from spatial covariance of the velocity and temperature fields is estimated independently from repeat hydrographic and expendable bathythermograph (XBT) sections and can also be approximated by the array.

The results for the $3.5 \mathrm{yr}$ of data thus far available show a mean MHT of $1.33 \pm 0.40 \mathrm{PW}$ for 10-dayaveraged estimates, on which time scale a basinwide mass balance can be reasonably assumed. The associated MOC strength and variability is $18.5 \pm 4.9 \mathrm{~Sv}\left(1 \mathrm{~Sv} \equiv 10^{6} \mathrm{~m}^{3} \mathrm{~s}^{-1}\right)$. The continuous heat transport estimates range from a minimum of 0.2 to a maximum of $2.5 \mathrm{PW}$, with approximately half of the variance caused by Ekman transport changes and half caused by changes in the geostrophic circulation. The data suggest a seasonal cycle of the MHT with a maximum in summer (July-September) and minimum in late winter (MarchApril), with an annual range of 0.6 PW. A breakdown of the MHT into "overturning" and "gyre" components shows that the overturning component carries $88 \%$ of the total heat transport. The overall uncertainty of the annual mean MHT for the 3.5-yr record is $0.14 \mathrm{PW}$ or about $10 \%$ of the mean value.
\end{abstract}

\section{Introduction}

The large-scale circulation of the ocean plays an important role in the meridional transport of water properties such as heat, freshwater, carbon, and nutrients. At $26^{\circ} \mathrm{N}$, where the Atlantic Ocean heat transport is close to its maximum, the circulation carries about $1.3 \mathrm{PW}$ $\left(1 \mathrm{PW}=10^{15} \mathrm{~W}\right)$ of heat northward (Lavin et al. 1998). This is approximately $70 \%$ of the net poleward heat flux carried by the global oceans and $25 \%$ of the total heat

Corresponding author address: William E. Johns, Division of Meteorology and Physical Oceanography, Rosenstiel School of Marine and Atmospheric Science, 4600 Rickenbacker Causeway, Miami, FL 33149.

E-mail: bjohns@rsmas.miami.edu flux by the ocean and the atmosphere at this latitude (Ganachaud and Wunsch 2003; Trenberth et al. 2001). This poleward heat flux is dominated by the meridional overturning circulation (MOC), in which thermocline waters moving northward in the basin are transformed into North Atlantic Deep Water (NADW) and transported southward below about $1000 \mathrm{~m}$.

Previous direct estimates of the ocean heat transport in the Atlantic, as well as in the other ocean basins, have been derived primarily from individual transbasin hydrographic sections or from inverse models combining multiple hydrographic sections. In the Atlantic, the available estimates of meridional heat transport (MHT) from these studies range from about 1.1 to $1.4 \mathrm{PW}$ at $24^{\circ}-26^{\circ} \mathrm{N}$, with typical uncertainties of $0.3 \mathrm{PW}$ (Hall and Bryden 1982; Lavin et al. 1998; Ganachaud and Wunsch 

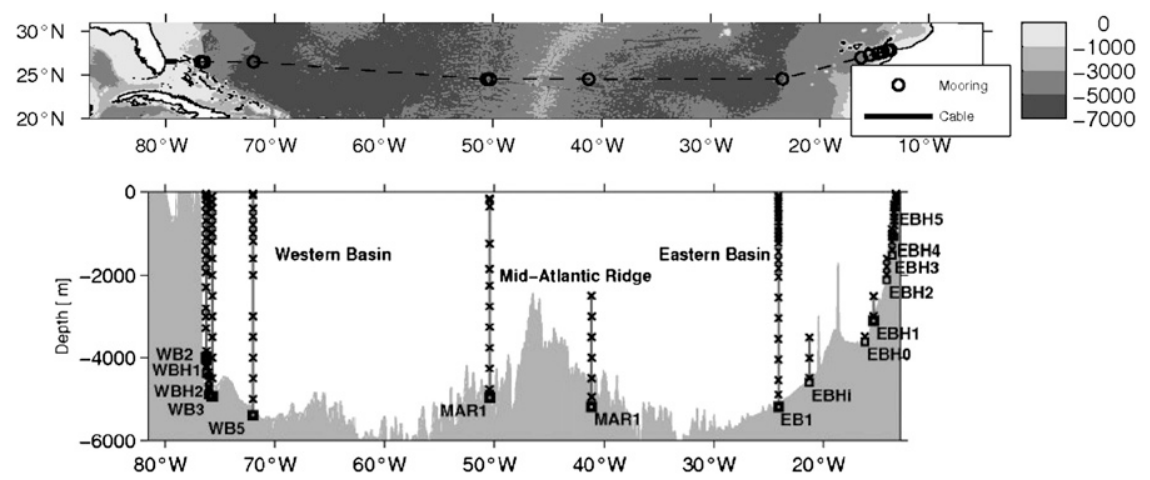

FIG. 1. RAPID-MOCHA interior mooring locations (top) across the basin and in (bottom) cross-section view superimposed on the section topography. Instrument locations on the moorings are denoted by " $x$." The western boundary array is shown in greater detail in Fig. 2 .

2003; Lumpkin and Speer 2007). Indirect estimates derived from surface flux climatologies or top-of-the-atmosphere radiation measurements give a somewhat broader range of estimates with larger uncertainties (Bryden and Imawaki 2001).

Variability of ocean heat transport remains largely unknown but is obviously an important factor in longterm climate variability. The most recent assessment from coupled climate models [Intergovernmental Panel on Climate Change (IPCC) Fourth Assessment Report (AR4); Meehl et al. 2007) is that greenhouse warming will lead to a decrease in the strength of the Atlantic MOC by $25 \%$ in the next century (Schmittner et al. 2005). This will presumably lead to a similar decrease in the Atlantic MHT, unless compensated by increased gyre or eddy circulations (Drijfhout and Hazeleger 2006).

On decadal-to-multidecadal time scales, there is growing model evidence that large-scale interhemispheric sea surface temperature (SST) anomalies in the Atlantic are linked to MOC and corresponding MHT variations (Knight et al. 2005; Zhang and Delworth 2006). Since ocean heat transport changes, by nature, lead ocean heat storage tendencies that can feed back to the atmosphere, an ability to accurately monitor the ocean heat transport will be important to future climate prediction efforts.

Until recently, there had been no in situ network capable of continuously monitoring ocean heat transport anywhere in the global oceans. Beginning in 2004, an observational array was deployed in the Atlantic Ocean along $26.5^{\circ} \mathrm{N}$ with the purpose of continuously monitoring the MOC at this latitude (Cunningham et al. 2007; Kanzow et al. 2007; Kanzow et al. 2008). While designed primarily to monitor the MOC, the data from this array can also be used to produce estimates of the MHT. In this paper, we show how estimates of the MHT are derived from this array and describe the 3.5-yr time series of MHT estimates thus far available (from April 2004 to
October 2007). In particular, we show that the continuous measurements provide a substantially reduced uncertainty in the MHT estimate with respect to one-time estimates from hydrographic sections. The resulting time series and mean MHT estimate over the 3.5-yr period should provide an important benchmark for indirect estimates derived from surface climatologies and residual methods and for comparison with numerical models.

\section{Data}

\section{a. RAPID-MOCHA}

The Rapid Climate Change-Meridional Overturning Circulation and Heatflux Array (RAPID-MOCHA) transbasin observing array was installed along $26.5^{\circ} \mathrm{N}$ in April 2004 and has been continuously operating since then. This paper treats the first $3.5 \mathrm{yr}$ of data, from April 2004 through October 2007. The overall strategy for RAPID-MOCHA consists of the use of endpoint "dynamic height" moorings on either side of the basin to monitor the basinwide geostrophic shear (Fig. 1), combined with moorings on the Bahamian continental margin (Fig. 2) and cable-derived measurements of the flow through the Straits of Florida (Fig. 3). Moorings are also included on the flanks of the mid-Atlantic Ridge to resolve flows in either subbasin. Ekman transports derived from satellite winds are then combined with the geostrophic and direct current observations and an overall mass conservation constraint to continuously estimate the basinwide MOC strength and vertical structure (Cunningham et al. 2007). Precision bottom pressure gauges are also employed to monitor absolute transports including barotropic circulation (Kanzow et al. 2007). The methodology for estimating the MOC is described in detail in Kanzow et al. (2010), where an analysis of the 


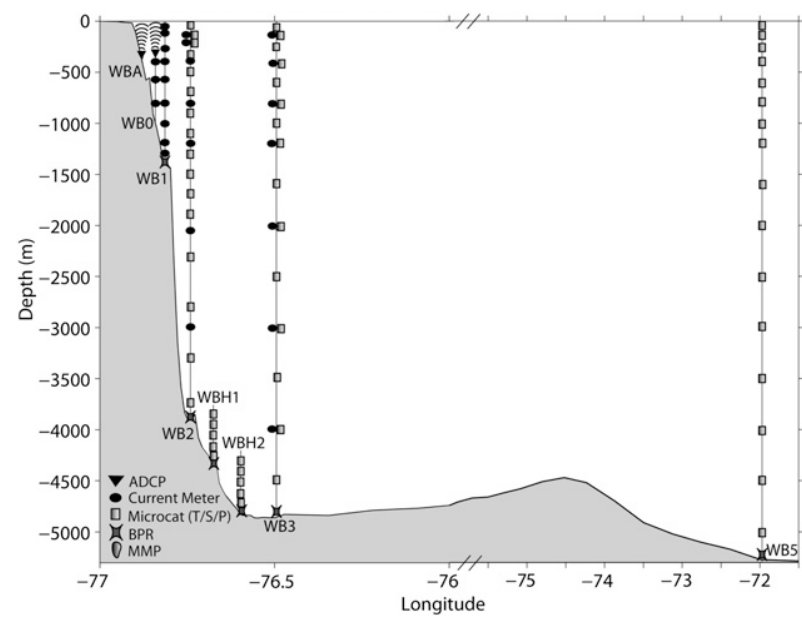

FIG. 2. Expanded view of the western boundary array off Abaco, Bahamas, with instrument types and depths. The longitude axis is nonlinear, changing at $76^{\circ} \mathrm{W}$.

MOC variability for the same period described here is presented. We provide a brief overview of the observing system elements here but refer the reader to Kanzow et al. (2010) for details on instrument calibrations, the methodology for computing the transport components involved in the MOC estimate, and the structure and variability of the MOC at $26.5^{\circ} \mathrm{N}$ during this period.

\section{b. Florida Current}

The transport of the Florida Current at $27^{\circ} \mathrm{N}$ has been monitored nearly continuously since 1982 using electromagnetic induction on subsea telephone cables between the Florida coast and the Little Bahama Bank (Fig. 3; Baringer and Larsen 2001; Meinen et al. 2010). The cable voltage difference is calibrated against observed volume transports across $27^{\circ} \mathrm{N}$ obtained from $6-10 \mathrm{cal}-$ ibration cruises performed each year, using dropsonde and direct current-profiling techniques. The accuracy of the daily cable-derived transport is approximately $\pm 2 \mathrm{~Sv}\left(1 \mathrm{~Sv} \equiv 10^{6} \mathrm{~m}^{3} \mathrm{~s}^{-1}\right)$, after removing tidal fluctuations.

The calibration cruises themselves provide a large number of direct velocity and temperature sections across the Florida Current at the repeat stations shown in Fig. 3, which are available to analyze the thermal properties of the current. These data are used in section 3a to construct a seasonal climatology of the flow-weighted temperature of the Florida Current, which is combined with the cable-derived volume transport to estimate the associated temperature transport through the Straits of Florida.

\section{c. The midocean array}

The interior ocean is monitored by an array of moorings measuring temperature and salinity at discrete depths near the eastern and western boundaries and on both flanks of the mid-Atlantic Ridge (Fig. 1). At the western boundary the $T-S$ data are combined from mooring WB2 above $4000 \mathrm{~m}$ and from moorings WBH1/ WBH2 below $4000 \mathrm{~m}$ to create a merged $T-S$ profile from $4800 \mathrm{~m}$ to the shallowest measurement level (nominally at $50 \mathrm{~m}$ ). Similarly, the moorings climbing up the slope of the eastern boundary (beginning with the bottom of mooring EB1 up to EBH5; Fig. 1) are used to construct a time-varying eastern boundary $T-S$ profile. Vertical profiles of density at the western and eastern boundaries and on western and eastern flanks of the mid-Atlantic Ridge are then used to compute basinwideintegrated northward geostrophic transports relative to

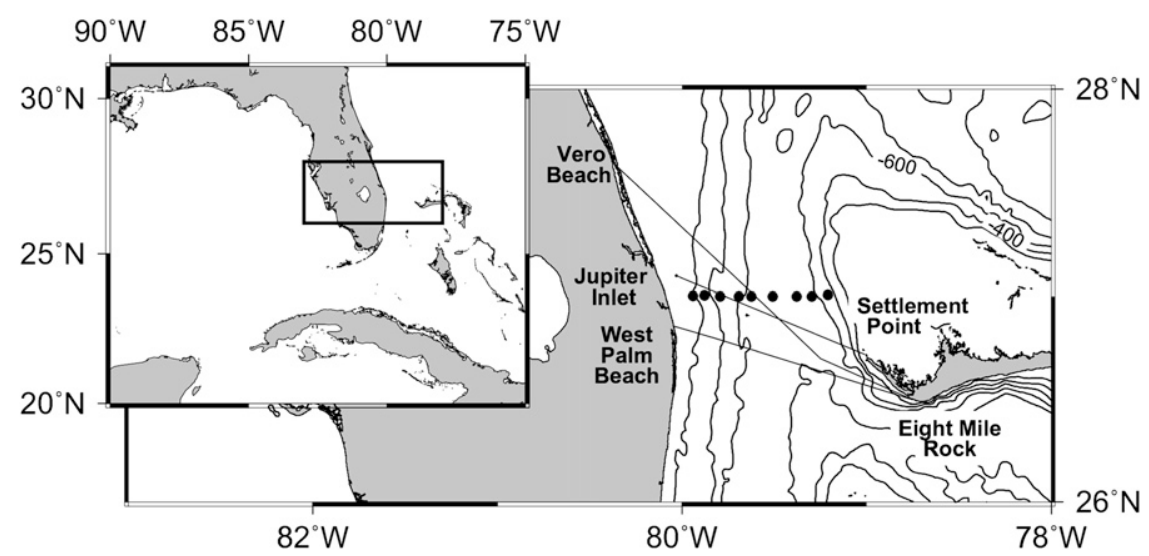

FIG. 3. Subsea telephone cables across the Straits of Florida. The West Palm Beach to Eight Mile Rock cable has been in operation since 1991 and provides the Florida Current transport measurements for the RAPID-MOCHA program. Cable calibration cruises are regularly performed along $27^{\circ} \mathrm{N}$, at the indicated profiling stations (dots). 
a deep reference level $(4740 \mathrm{~m})$. Creation of the continuous $T$ and $S$ profiles at the moorings involves a special vertical interpolation procedure utilizing regionally dependent background $d T / d z$ and $T-S$ climatologies (Johns et al. 2005; Kanzow et al. 2006). The accuracy of the top-to-bottom relative geostrophic transport from this method is approximately $\pm 2.5 \mathrm{~Sv}$. Transports of Antarctic Bottom Water at depths greater than $5000 \mathrm{~m}$ are accounted for by extending the transport profile to $6000 \mathrm{~m}$ using historical estimates (Kanzow et al. 2010).

The zonally averaged interior transport profile is referenced by enforcing a basinwide mass balance on sufficiently long time scales ( $>10$ days; see Kanzow et al. 2007), such that all computed mass transport components (Florida Current, ocean interior, Ekman, and Bahamas boundary layer-to be described shortly) sum to zero. This mass balance is enforced by adding a spatially uniform compensating velocity across the entire midocean section to the baroclinic profile, to account for the interior barotropic component of flow. Independent measurements of the midocean barotropic transport from the array of bottom pressure gauges across the section show that it compensates the variability in the other transport components within expected uncertainties (Kanzow et al. 2007). However, since meaningful heat transport estimates require an exact mass closure, an exact mass compensation using a spatially uniform velocity is applied. The resulting zonally averaged interior transport profile is used here in the calculation of the main portion of the interior ocean temperature transport (section 3a).

\section{d. Western boundary array}

At the edge of the Bahamas escarpment, moorings WBA to WB2 make up a closely spaced western boundary component of the interior array. Moorings WB0, WB1, and WB2 are equipped with current meters and temperature or $T-S$ sensors at discrete depths through the water column, and WBA and WB0 contain upward-looking ADCPs in the top $500 \mathrm{~m}$. The role of these measurements within the system is to monitor the time-varying transport and temperature structure in the region shoreward of WB2, which is the western endpoint for the midocean region. The upper portion of the water column over the Bahamas escarpment contains a strong northward mean flow associated with the Antilles Current, while the deeper part contains a portion of the abyssal southward flow associated with the Deep Western Boundary Current (DWBC; most of which, however, lies to the east of mooring WB2 within our midocean domain). Transports calculated for this western boundary region, referred to hereafter as the western boundary wedge, are estimated to be accurate to within $\pm 0.5 \mathrm{~Sv}$ (Johns et al. 2008).

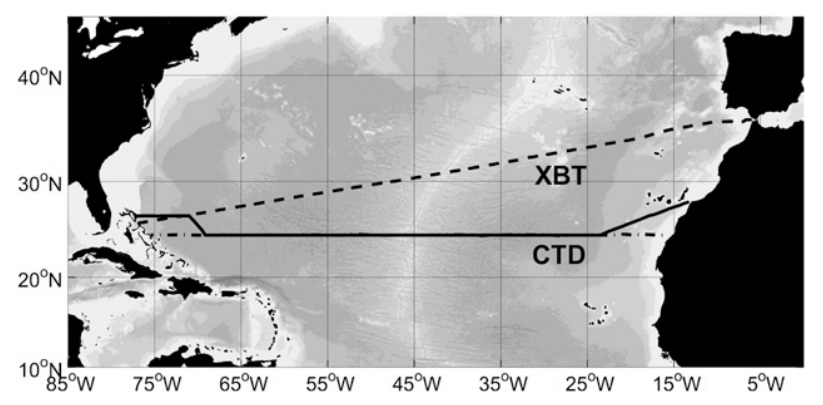

FIG. 4. Locations of transbasin CTD sections along $24^{\circ}-26^{\circ} \mathrm{N}$, and the AX-7 high-density XBT line across the Atlantic between Miami and Gibraltar, which are used to estimate the interior eddy heat flux contribution to the basinwide meridional heat transport. The earlier CTD sections (1957 and 1981) were occupied along $24^{\circ} \mathrm{N}$ (dot-dashed line); later sections $(1992,1998$, and 2004) deviated from $24^{\circ} \mathrm{N}$ near the boundaries to intersect the coasts near $26.5^{\circ} \mathrm{N}$ (solid line).

The remainder of the western boundary array consists of two tall moorings (WB3 and WB5) that contain vertical arrays of $T-S$ recorders, as well as current meters on WB3. Mooring WB3 serves as a backup dynamic height mooring for WB2 and also provides direct velocity measurements near the mean core of the DWBC. WB5 is deployed well offshore of the Bahamas to provide a dynamic height profile at the outer edge of the western boundary layer, to capture transport variability associated with offshore meandering of the DWBC and localized recirculation cells adjacent to the western boundary (Johns et al. 2008).

\section{e. Ancillary data}

\section{1) $24^{\circ}-26^{\circ} \mathrm{N}$ CTD SECTIONS}

Between 1957 and 2004, five transoceanic conductivitytemperature-depth (CTD) sections were acquired along latitudes $24^{\circ}-26^{\circ} \mathrm{N}$ in the Atlantic (Fig. 4). These sections are used here to estimate the part of the interior ocean temperature flux that is caused by spatially correlated velocity and temperature anomalies, the so-called eddy heat flux contribution (Hall and Bryden 1982). The sections were nominally occupied along $24^{\circ} \mathrm{N}$, but the more recent ones $(1992,1998$, and 2004) deviated from $24^{\circ} \mathrm{N}$ to intersect the western and eastern boundaries near $26.5^{\circ} \mathrm{N}$. A consistent reanalysis of these sections has been performed following the procedures applied to the 1957, 1981, and 1992 sections by Lavin et al. (1998). Earlier results from these sections may be found in Lavin et al. (1998), Lavin et al. (2003), Roemmich and Wunsch (1985), and Bryden et al. (2005), among others.

Using the data available from these CTD sections, as well as all other historical hydrographic data across the ocean interior near these latitudes, a new RAPID hydrographic 


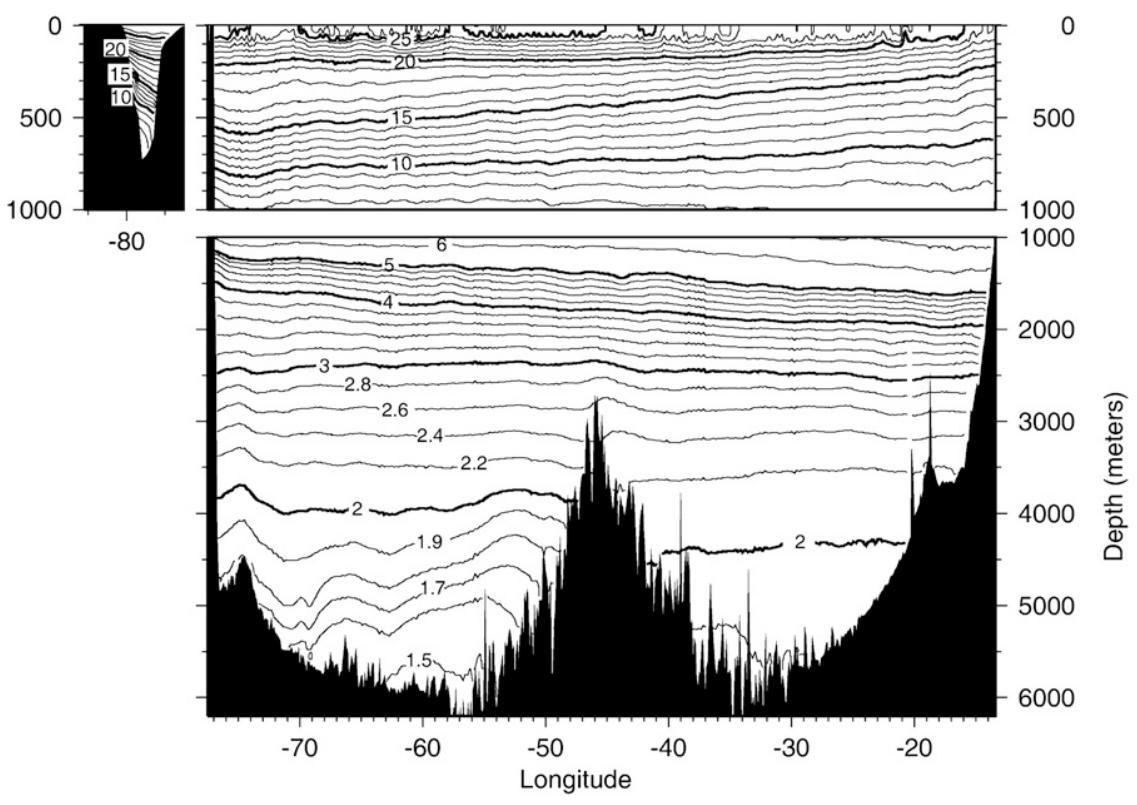

FIG. 5. Potential temperature structure along the RAPID-MOCHA line, derived from a Hydrobase climatology of all available CTD and station data collected near the line. (left) The Straits of Florida and (top) the upper ocean on an expanded scale are shown.

climatology was produced using the "Hydrobase" data analysis package (Curry 1996). Three-dimensional fields of pressure, temperature, and salinity were constructed by objective mapping of the available measurements along isopycnal surfaces at 0.2 degree resolution, using spatial decorrelation scales of $200 \mathrm{~km}$ in the upper $1000 \mathrm{~m}$ and $500 \mathrm{~km}$ for deeper levels. For the upper $200 \mathrm{~m}$ of the water column, the analysis was performed on a month-bymonth basis. This seasonal climatology is subsequently used in section $3 \mathrm{a}$ with the zonally averaged geostrophic flow derived from the array to estimate the interior ocean temperature flux. The annual mean temperature along the RAPID-MOCHA line derived from the climatology is shown in Fig. 5.

\section{2) RepeAt XBT SECTIONS ALONG AX-7 (MIAMI-GIBRALTAR)}

Since 1995, a large number of high-resolution $\left(0.5^{\circ}\right.$ zonal spacing) expendable bathythermograph (XBT) sections have been acquired along a volunteer observing ship line running between Miami and Gibraltar. This section, termed the AX-7 line (Fig. 4), is run an average of 4 times per year, approximately on a quarterly basis, providing upper-ocean temperature profiles to $\sim 800 \mathrm{~m}$. A subset of 13 sections that took place during 2004-07 is used in a manner analogous to the $24^{\circ} \mathrm{N}$ CTD section data to estimate the magnitude and variability of the interior "eddy" heat flux near the latitude of the RAPIDMOCHA line. Geostrophic velocity estimates are produced from the XBT sections by applying a zonally varying $T-S$ climatology to the data and merging it with a deep-water climatology below $800 \mathrm{~m}$ based on the World Ocean Atlas 2001 (Conkright et al. 2002). As shown in section $3 \mathrm{a}$, nearly all of the interior eddy heat flux contribution is contained in the upper $1000 \mathrm{~m}$ of the ocean, and therefore the XBT sections are able to capture most of this contribution.

\section{3) SATElLite DATA}

\section{(i) Scatterometry}

Zonal winds stress data available from the National Aeronautics and Space Administration (NASA)'s Quick Scatterometer (QuikSCAT) satellite mission are used to generate daily estimates of meridional Ekman transport across $26.5^{\circ} \mathrm{N}$, which are subsequently used in both the MOC and MHT calculations. The wind stress estimates were computed and gridded by the European Space Agency Processing and Archiving Facility (CERSAT)/ IFREMER, France (http://www.ifremer.fr/cersat/en/ index.htm) based on level-2 neutral wind swath data distributed by the Physical Oceanography Distributed Active Archive Center (PO.DAAC; http://podaac.jpl. nasa.gov/). The resolution of the CERSAT gridded data is $0.5^{\circ}$ longitude by $0.5^{\circ}$ latitude.

\section{(ii) $S S T$}

Satellite sea surface temperature fields merged with available in situ SST data (Reynolds and Smith 1994) are 
available on a global grid from the National Oceanic and Atmospheric Administration (NOAA)/Earth System Research Laboratory (ESRL) at weekly temporal resolution. The zonal resolution of the data is $1^{\circ}$ longitude. The data are interpolated onto $26.5^{\circ} \mathrm{N}$ and then interpolated to daily values and the same $0.5^{\circ}$ longitude grid as the QuikSCAT data, whereupon it is combined with the Ekman transports to generate daily estimates of the Ekman-layer temperature flux (section 3a).

\section{Results}

\section{a. Calculation of the meridional heat transport}

The meridional heat transport is defined by

$$
Q_{\mathrm{NET}}=\iint \rho c_{p} v \theta d x d z
$$

where $\rho$ is seawater density, $c_{p}$ is the specific heat of seawater, $v$ is meridional velocity, $\theta$ is potential temperature, and where the double integral is taken over the full area of the transbasin section. Here, we break this total heat transport down into a number of separate components, which individually represent temperature transports relative to a specified temperature reference. Only when the mass fluxes of these components balance and they are summed together do these temperature transports yield a meaningful heat transport value. This breakdown is

$$
Q_{\mathrm{NET}}=Q_{\mathrm{FC}}+Q_{\mathrm{EK}}+Q_{\mathrm{WB}}+Q_{\mathrm{MO}}+Q_{\mathrm{EDDY}},
$$

where the different terms represent, respectively, the meridional temperature transports of the Florida Current $\left(Q_{\mathrm{FC}}\right)$, the Ekman layer $\left(Q_{\mathrm{EK}}\right)$, the western boundary wedge over the Bahamas escarpment $\left(Q_{\mathrm{WB}}\right)$, the zonally averaged contribution by the midocean circulation $\left(Q_{\mathrm{MO}}\right)$, and the midocean eddy contribution due to spatially correlated $v$ and $\theta$ fluctuations $\left(Q_{\mathrm{EDDY}}\right)$. The latter term is a true heat transport since it has no mass transport associated with it and is independent of temperature reference. In reality, there is a net transport across the $26.5^{\circ} \mathrm{N}$ section owing to the Bering Strait throughflow to the Arctic, of approximately 1.0 Sv southward. This results in a small correction to the $Q_{\mathrm{NET}}$ expressed by (1), of $\sim-0.02$ PW (Hall and Bryden 1982). We return to this point in the discussion, however, for the moment we focus on the heat transport carried by the massconserving flow across the section.

In what follows, we describe how each of the terms in (1) is estimated and discuss their variability. Much of our treatment will deal with temperature transports relative to a reference of $0^{\circ} \mathrm{C}$; however, we also calculate these relative to the average midocean temperature $\left(5.33^{\circ} \mathrm{C}\right.$ as derived from our RAPID interior climatology).
TABLE 1. Mean values and standard deviations of temperature transport components that are combined to estimate the total, basinwide meridional heat transport. Units of PW ( $10^{15}$ watts).

\begin{tabular}{lcc}
\hline $\begin{array}{c}\text { Meridional } \\
\text { heat transport } \\
\text { component }\end{array}$ & $\begin{array}{c}\text { Temperature } \\
\text { transport } \\
\text { (relative to } 0{ }^{\circ} \mathrm{C} \text { ) }\end{array}$ & $\begin{array}{c}\text { Temperature } \\
\text { transport } \\
\text { (relative to } \theta_{\text {midocean }} \text { ) }\end{array}$ \\
\hline Florida Current & $2.53 \pm 0.24$ & $1.84 \pm 0.18$ \\
Ekman & $0.35 \pm 0.34$ & $0.27 \pm 0.27$ \\
Midocean & $-1.77 \pm 0.25$ & $-0.97 \pm 0.20$ \\
WB-Abaco & $0.13 \pm 0.16$ & $0.10 \pm 0.11$ \\
Eddy* & $0.11 \pm 0.04$ & $0.11 \pm 0.04$ \\
Total* & $1.35 \pm 0.40$ & $1.35 \pm 0.40$ \\
\hline
\end{tabular}

* Independent of temperature reference

Both temperature references are commonly used in the literature. Temperature transports calculated relative to the average midocean temperature are sometimes termed "mass neutral" fluxes, under the assumption that any mass transport associated with them is returned across the section at the average midocean temperature. While we refer to these as temperature transports to maintain the distinction to heat transports, they are still multiplied by $\rho c_{p}$ and therefore have units of heat transport (expressed here in PW). In all of the calculations and plots described, these temperature transports, and the resulting net heat transport, are low-pass filtered with a 10-daycutoff Butterworth filter. Thus, time scales less than 10 days, where the assumption of mass compensation used in referencing the interior transports may not hold (Kanzow et al. 2007), are excluded from consideration and do not contribute to the quoted variances. Table 1 contains the mean values and standard deviations of each of these contributions, relative to both temperature references, and the corresponding net heat transport values. A constant value of $\rho c_{p}=4.1 \times 10^{6} \mathrm{~J} \mathrm{~kg}^{-1}{ }^{\circ} \mathrm{C}^{-1}$ was used in all heat transport calculations.

\section{1) Florida CURRENT TEMPERATURE TRANSPORT}

The subsea cable voltages provide the only continuous means of monitoring the Florida Current and therefore form the basis of our $Q_{\mathrm{FC}}$ estimate. Shoosmith et al. (2005) investigated several methods for estimating $Q_{\mathrm{FC}}$ from the cable-derived voltages. These included the following: 1) a direct regression of the cable voltages against in situ measured temperature transports, 2) multiplication of the cable-derived volume transport by the average flow-weighted temperature $\left(\sim 19.4^{\circ} \mathrm{C}\right)$ of the Florida Current, and 3) multiplication of the cablederived volume transport by a seasonally varying flowweighted temperature. Of the three methods, the third proved to be the most accurate by a small margin, and we adopt that same approach here. 


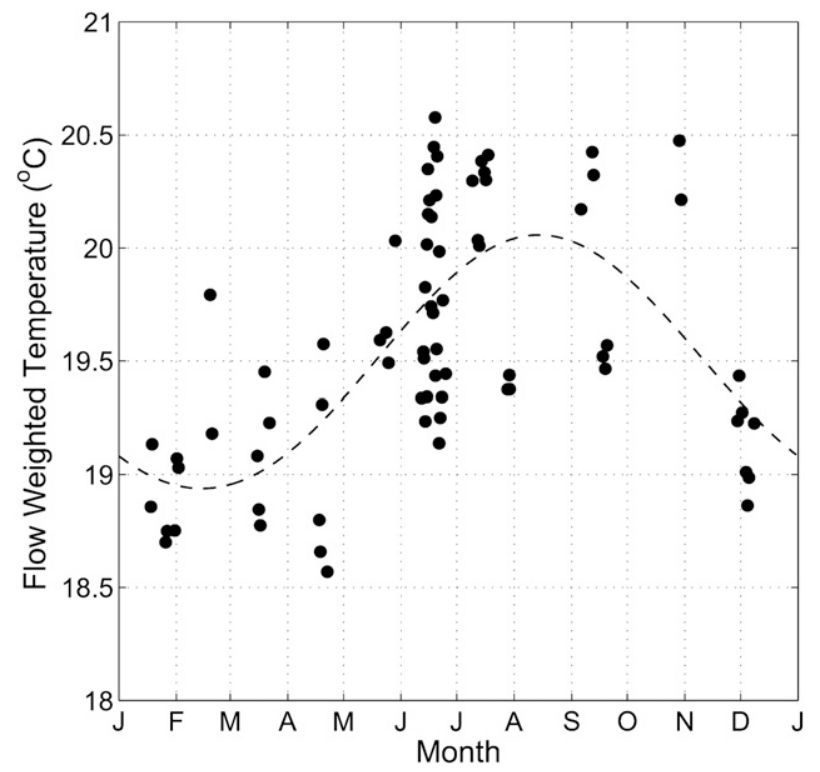

FIG. 6. Seasonal variation of the flow-weighted temperature $\left(\theta_{\mathrm{FW}}\right)$ of the Florida Current (dashed line) based on the ensemble of available direct velocity and temperature sections acquired during cable calibration cruises (dots).

Using a large number (84) of available direct velocity and temperature cross sections of the straits at $27^{\circ} \mathrm{N}$ (including several not available to Shoosmith et al.), we compute, for each section, the flow-weighted temperature of the current:

$$
\theta_{\mathrm{FW}}=\iint v \theta d x d z / \iint v d x d z
$$

The seasonal distribution of these values is shown in Fig. 6 along with a best-fit seasonal cycle composed of the sum of an annual and semiannual harmonic. Although much of the variability of $\theta_{\mathrm{FW}}$ appears to be random, covering a range of some $2^{\circ} \mathrm{C}$, there is an identifiable seasonal cycle with maximum flow-weighted temperatures occurring in boreal summer and fall and minimum temperatures in late winter and spring, consistent with expectations based on the seasonal heating/cooling cycle. The mean value of $\theta_{\mathrm{FW}}$ is $19.4^{\circ} \mathrm{C}$, and the amplitude of this seasonal cycle is $0.5^{\circ} \mathrm{C}$.

Using this seasonal climatology for $\theta_{\mathrm{FW}}$, estimates of $Q_{\text {FC }}$ for each section are formed by multiplying the cable-derived volume transport at the time of each section by the respective seasonal $\theta_{\mathrm{FW}}$ value. These values can be compared to the original in situ derived $Q_{\mathrm{FC}}$ values to assess their accuracy. The regression of the cable-derived $Q_{\mathrm{FC}}$ versus the observed $Q_{\mathrm{FC}}$ (Fig. 7) shows an $r^{2}$ of 0.88 and a root-mean-square (rms) error of $0.10 \mathrm{PW}$. Therefore, temperature transports for the Florida Current can be derived from the cable with an average accuracy of $\pm 0.1 \mathrm{PW}$.

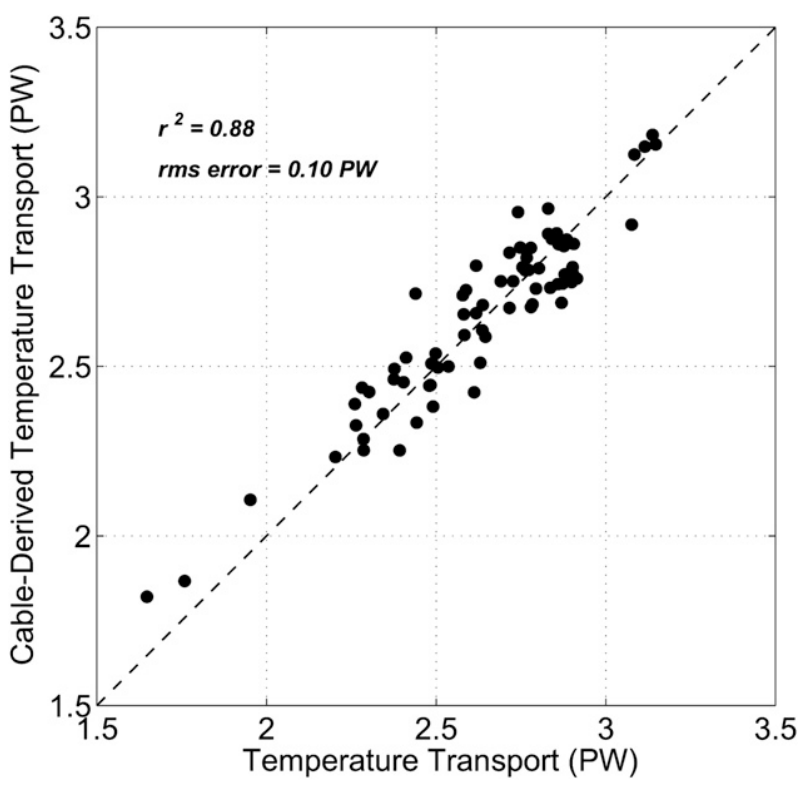

FIG. 7. Cable-derived temperature transport of the Florida Current $\left(Q_{\mathrm{FC}}\right)$ vs the directly measured temperature transport from simultaneous cable calibration cruises.

The continuous estimates derived from the cable for the first $3.5 \mathrm{yr}$ of the array are shown in Fig. 8. The mean value and standard deviation of $Q_{\mathrm{FC}}$ is $2.53 \pm 0.24 \mathrm{PW}$ (Table 1). The corresponding mean volume transport is $31.7 \pm 2.8 \mathrm{~Sv}$. Most of the $Q_{\mathrm{FC}}$ variability is directly linked to the transport variability of the Florida Current, owing to the relatively small variation of the flowweighted temperature. However, the $Q_{\mathrm{FC}}$ variability will be somewhat underestimated by the use of a smoothly varying $\theta_{\mathrm{FW}}$ rather than an instantaneously varying $\theta_{\mathrm{FW}}$. Taking into account the $O\left( \pm 1^{\circ} \mathrm{C}\right)$ noise about the seasonal cycle of $\theta_{\mathrm{FW}}$, and an average Florida Current transport of $32 \mathrm{~Sv}$, it can be estimated that the additional missing variance would lead to a standard deviation of about $0.27 \mathrm{PW}$, not greatly different than the calculated $0.24 \mathrm{PW}$. This additional variability is also expected to be contained mainly on short time scales and should have little effect on the low-frequency variability of the record.

\section{2) EKMAN TEMPERATURE TRANSPORT}

The temperature transport in the Ekman layer is estimated by

$$
Q_{\mathrm{EK}}=\int\left(c_{p} / f\right) \tau_{x} \theta_{\mathrm{EK}} d x,
$$

where $f$ is the Coriolis parameter, $\tau_{x}$ is zonal wind stress derived from QuikSCAT, and $\theta_{\mathrm{EK}}$ is SST from Reynolds and Smith 1994, as described in section 2. The integral is performed daily across the basin between the Bahamas 


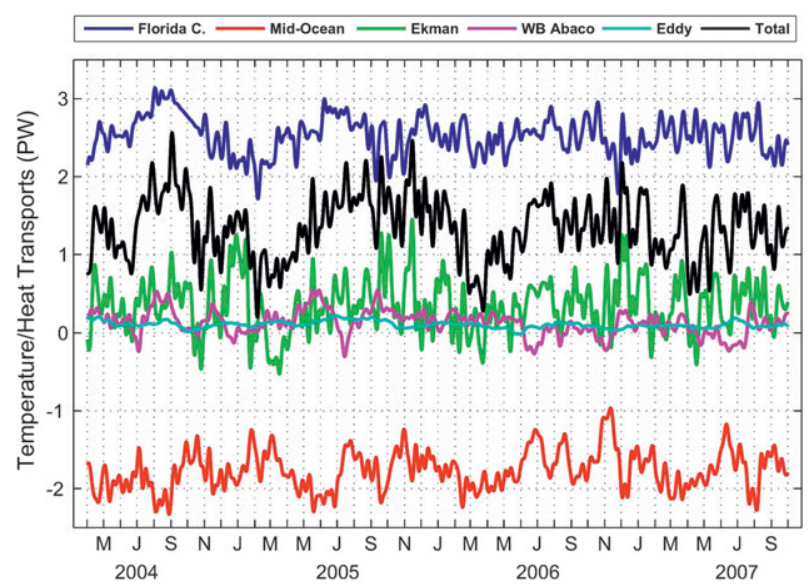

FIG. 8. Temperature transports (relative to $0^{\circ} \mathrm{C}$ ), for each of the section contributions to the net meridional heat transport at $26.5^{\circ} \mathrm{N}$ (shown in black line). See text for definitions of the individual components. All components have been low-pass filtered to remove variance at periods shorter than 10 days. The total heat transport (black) and midocean eddy heat transport (light blue) are the only ones that represent true heat fluxes, independent of temperature reference.

and Africa, at $0.5^{\circ}$ zonal resolution, and the result is then filtered with a 10-day low-pass filter as described above (Fig. 8). Earlier work has shown that using a single bulk mixed layer temperature value with a bulk Ekman transport results in very small (negligible, with respect to our overall calculation) errors in the derived temperature flux carried in the Ekman layer (Wijffels et al. 1994). We also find that there are only small differences between our calculated $Q_{\mathrm{EK}}$, which takes into account zonal variations of both the Ekman transport and the SST, and a simpler estimate formed from the zonally averaged Ekman transport and zonally averaged SST at each time step. Therefore, at this latitude, the details of how this calculation is performed do not substantially impact the results.

The Ekman temperature transport varies between -0.5 to $1.2 \mathrm{PW}$, with considerable short-term (intraseasonal) variability (Fig. 8). Its mean value is $0.35 \mathrm{PW}$, which is associated with a mean northward Ekman transport of 3.5 Sv. Similar to the findings for the Florida Current, most of the variability of $Q_{\mathrm{EK}}$ is accounted for by the Ekman transport variability itself.

\section{3) TEMPERATURE TRANSPORT IN THE WESTERN BOUNDARY WEDGE}

Temperature transports in the western boundary wedge adjacent to the Bahamas escarpment are calculated from directly measured temperatures and currents within the western boundary subarray described in section 2 . The procedure is analogous to the method by which transports are estimated for this region (Johns et al. 2008).
Currents are mapped onto a regular $(20 \mathrm{~m} \times 2 \mathrm{~km})$ grid over the domain and extended to the surface by constant shear, and temperatures are interpolated vertically on the moorings following the same method used for the interior moorings (with inclusion of a surface data point taken from the Reynolds and Smith 1994 SST), then mapped to the same domain as the currents. Where temperature measurements were not available (e.g., in the upper water column at the ADCP sites; see Fig. 2), the temperature structure is extended shoreward with no change from the nearest offshore data. A direct integration of the $v \theta$ product over the domain at each time step then yields the wedge temperature transport $Q_{\mathrm{WB}}$.

While the mean value of $Q_{\mathrm{WB}}(0.13 \pm 0.16$; Table 1$)$ is relatively small, being associated with a mean northward transport in the wedge of only $1.3 \mathrm{~Sv}$, it has considerable variability (Fig. 8), mostly on time scales of several months that are typical of eddy time scales in this region (Lee et al. 1990, 1996). The volume transport in the wedge varies from -5.5 to $8.1 \mathrm{~Sv}$ over the 3.5 -yr period. Therefore, it is important to account for this region in the overall mass transport budget as well as in the total heat transport.

\section{4) Midocean TEMPERATURE TRANSPORT}

The temperature transport for the midocean region, here taken from mooring WB2 to the eastern boundary, can be divided into two terms: 1 ) a contribution from the zonally averaged velocity and temperature fields across the basin $\left(Q_{\mathrm{MO}}\right)$, and 2) a contribution resulting from spatial covariation of the velocity and temperature anomalies with respect to these zonal means ( $\left.Q_{\text {EDDY }}\right)$. Formally, these are written as

$$
\begin{aligned}
Q_{\mathrm{MO}} & =\iint \rho c_{p}\langle v\rangle\langle\theta\rangle d x d z=\int \rho c_{p} V\langle\theta\rangle d z \quad \text { and } \\
Q_{\mathrm{EDDY}} & =\iint \rho c_{p} v^{\prime} \theta^{\prime} d x d z,
\end{aligned}
$$

where $\langle v\rangle$ and $\langle\theta\rangle$ represent zonal averages of the velocity and potential temperature (both functions of depth), $v^{\prime}$ and $\theta^{\prime}$ are the anomalies from the zonal means (functions of $x$ and $z$ ), and where $Q_{\mathrm{MO}}$ can be expressed in terms of the zonally integrated transport per unit depth profile $V=\int v d x$.

Here, $Q_{\mathrm{MO}}$ is estimated by combining the basinwideintegrated transport profile $V(z)$ obtained from the interior mooring array, with the zonally averaged midocean temperature $\langle\theta\rangle(z)$. The midocean mooring array is too sparse by itself to construct a suitably accurate $\langle\theta\rangle(z)$ profile, and therefore we estimate this from the RAPID interior hydrographic climatology described earlier. The $\langle\theta\rangle(z)$ profile is obtained by integrating the seasonally varying temperature climatology across the 
ocean, interpolated to the same yearday as the observed $V(z)$ profile. The resulting $Q_{\mathrm{MO}}$ (Fig. 8) has a mean and standard deviation of $-1.77 \pm 0.25 \mathrm{PW}$. The mean value is large and negative (southward) and is associated mainly with the southward midocean transport of the subtropical gyre, which is surface intensified in the warm layers. The total southward volume transport over the midocean region is $-36.5 \pm 4.4 \mathrm{~Sv}$, made up of southward flows of $-18.6 \pm 3.0 \mathrm{~Sv}$ in the upper ocean $(0-800 \mathrm{~m})$ and $-20.6 \pm 4.4 \mathrm{~Sv}$ in the NADW layer $(1100-5000 \mathrm{~m})$, and northward flows of $0.5 \pm 0.6 \mathrm{~Sv}$ in the intermediate layer $(800-1100 \mathrm{~m})$ and $2.1 \pm 0.6 \mathrm{~Sv}$ in the bottom water layer (Kanzow et al. 2010).

Similar to the Florida Current temperature transport estimate, this method may underestimate the actual $Q_{\mathrm{MO}}$ variability since it neglects any nonseasonal variation of the basinwide mean temperature. To test the impact of this, the computation was done using each of the five available transbasin temperature sections along $24^{\circ}-26^{\circ} \mathrm{N}$ instead of the RAPID temperature climatology, and the result for the midocean temperature transport differs by no more than $0.04 \mathrm{PW}$. This is negligible compared to the variability of $Q_{\mathrm{MO}}( \pm 0.25 \mathrm{PW})$, nearly all of which is induced by the interior volume transport variability. The use of a seasonally varying interior climatology also has little impact on the results, but it is retained to eliminate any systematic seasonal bias that might otherwise occur.

Estimating $Q_{\mathrm{EDDY}}$ is the most challenging aspect of the MHT calculation. It requires measurements of the spatially varying $v$ and $\theta$ structure across the whole midocean section, which is something that the array does not provide. To investigate the size of $Q_{\mathrm{EDDY}}$ and how much it might be expected to vary in time, we use the data from the five available hydrographic sections along $24^{\circ}-26^{\circ} \mathrm{N}$ and the Miami-Gibraltar (AX-7) XBT sections, from which $Q_{\mathrm{EDDY}}$ can be directly estimated. It should be emphasized here that the term eddy heat flux is often used to represent a time-averaged flux at a certain location, arising from temporal covariation of $v$ and $\theta$, whereas here it denotes a spatially averaged flux at a certain time arising from spatial covariation of $v$ and $\theta$ along the whole section. This is the same definition used by Hall and Bryden (1982) and others in their treatment of MHT derived from individual hydrographic sections.

Estimates of $Q_{\text {EDDY }}$ derived from each of the five hydrographic sections are shown in Fig. 9a, where the total flux is accumulated eastward from the western boundary. (Since the sections do not all intersect the western boundary at the same longitude, they are plotted in terms of distance from the western boundary for easier comparison.) The mean value of $Q_{\mathrm{EDDY}}$ for the five sections is $0.10 \pm 0.03 \mathrm{PW}$. The structure of the
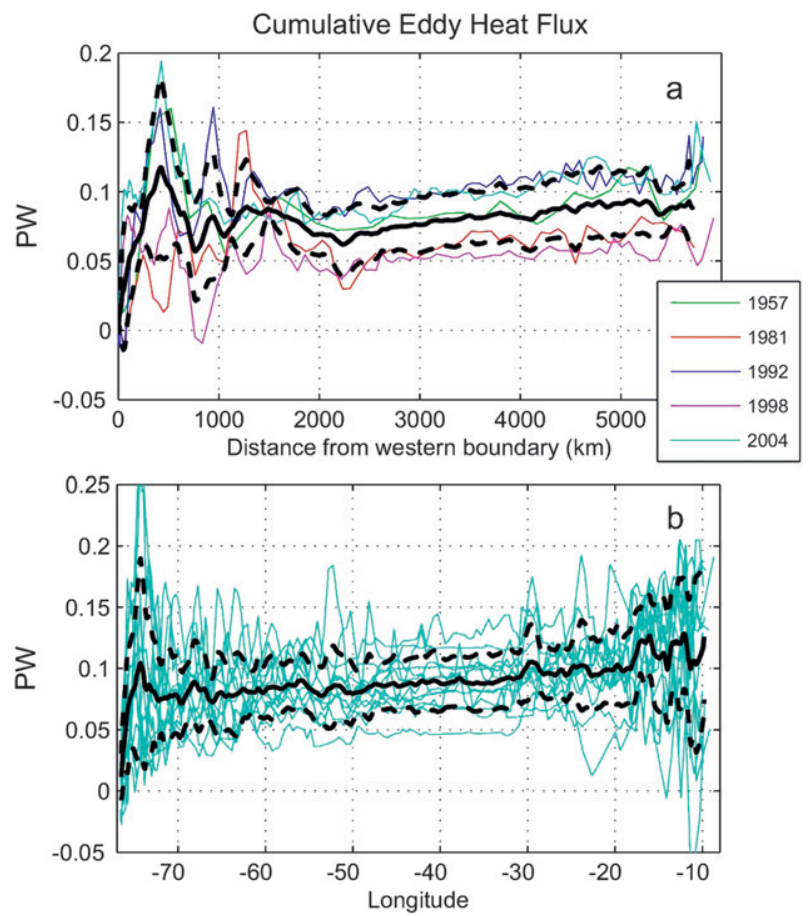

FIG. 9. (a) Cumulative interior ocean eddy heat flux ( $\left.Q_{\text {EDDY }}\right)$, summed from the western boundary to the eastern boundary, for the five CTD sections along $24^{\circ}-26^{\circ} \mathrm{N}$; (b) as in (a), but for the AX-7 repeat XBT line from Miami-Gibraltar. The colored lines represent individual sections; bold lines show the basinwide mean and standard deviation.

cumulative eddy heat flux across the basin-reflected in the individual sections as well their mean-consists of a rapid increase within a few hundred kilometers of the western boundary, followed by oscillations of an eddylike nature to $\sim 2000 \mathrm{~km}$ from the western boundary, and then a gradual further increase toward the eastern boundary. The overall structure is remarkably robust between the sections. The vertical profile of the zonally integrated flux (Fig. 10) shows that $Q_{\mathrm{EDDY}}$ is contained entirely within the upper $2000 \mathrm{~m}$ and mainly in the top $600-700 \mathrm{~m}$ of the water column.

To understand the reasons for the zonal structure seen in Fig. 9, we show in Fig. 11 the zonal profile of $v^{\prime}$ and $\theta^{\prime}$ averaged over the upper $1000 \mathrm{~m}$ for each of the five sections. The temperature field has a simple large-scale structure consisting of warm anomalies in the west of up to $1.5^{\circ} \mathrm{C}$ and progressively increasing cold anomalies to $>1.5^{\circ} \mathrm{C}$ in the east, associated with the tilt of the main thermocline across the basin (Fig. 5). The $v^{\prime}$ structure is considerably more complicated but shows a region of positive mean flow within about $500 \mathrm{~km}$ of the western boundary, followed by oscillations about a general (weak) southward flow anomaly. The main contribution to $Q_{\text {EDDY }}$ therefore appears to result from a large scale 


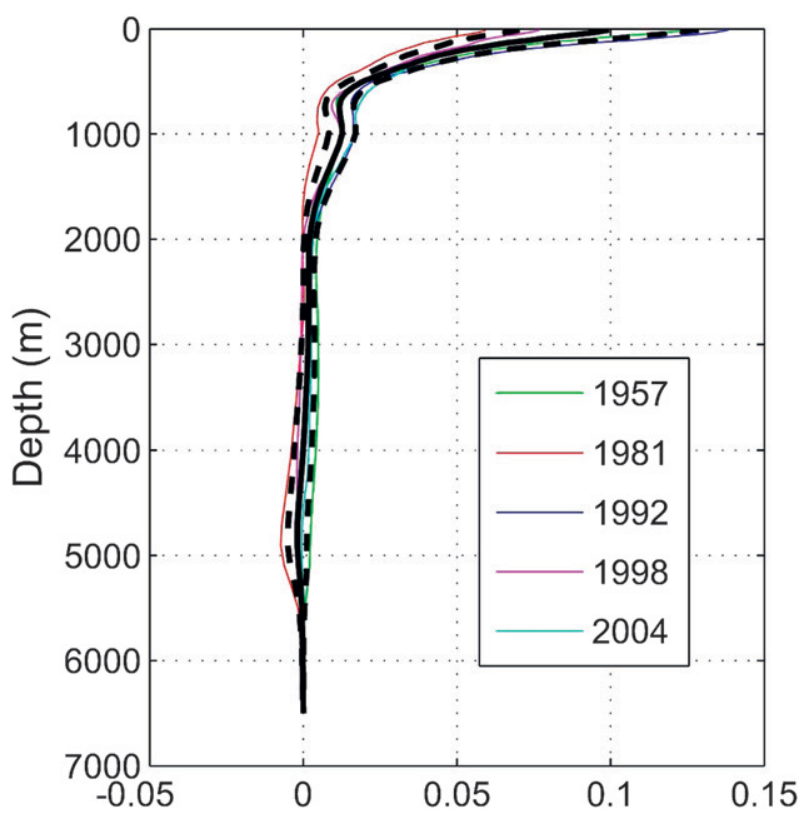

FIG. 10. Vertical structure of the interior eddy heat flux ( $\left.Q_{\text {EDDY }}\right)$ for the five CTD sections along $24^{\circ}-26^{\circ} \mathrm{N}$, accumulated upward from the bottom. Colored lines show the individual section results; bold lines show the mean and standard deviation of the profiles.

pattern of $v^{\prime}$ and $\theta^{\prime}$ rather than a rectified eddy flux due to randomly distributed mesoscale features. That is, if one considers the $v^{\prime}(x, t)$ and $\theta^{\prime}(x, t)$ fields to consist of one part that is quasi stationary in time and another that is fully time and space variable, the quasi-stationary pattern is the dominant contributor. We interpret this pattern as follows. The northward flow anomaly near the Bahamas is related to the Antilles Current, which represents a part of the northward western boundary return flow of the subtropical gyre that does not penetrate into the Caribbean to join the Florida Current (Böning et al. 1991; Johns et al. 2002). This positive $v^{\prime}$ together with the positive $\theta^{\prime}$ in this region results in the large accumulation of northward heat flux near the western boundary. The patterns in Figs. 9a and 11 suggest a region of recirculation with large eddies in the adjacent offshore region, and then a weak southward flow anomaly associated with the southward interior gyre flow and colder temperatures across the rest of the basin. This interpretation renders the name eddy heat transport inappropriate in the present case, but we retain it for consistency with historical terminology used by Hall and Bryden (1982) and others.

A similar structure is seen in the XBT sections (Fig. 9b), though with considerably larger variability in the eastern part of the section where the section enters the Gulf of Cadiz and an (apparently) eddy-rich environment there. However, most of the contribution again occurs
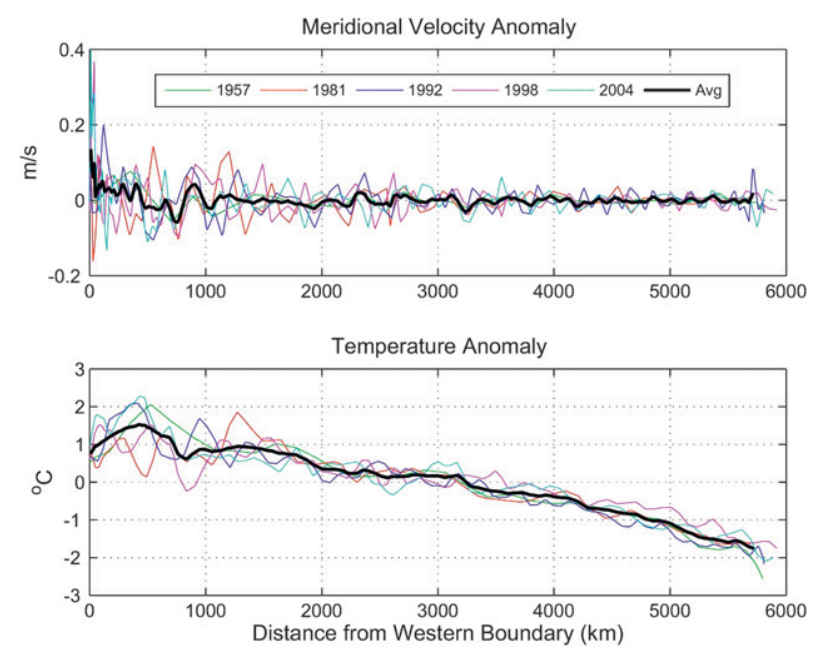

FIG. 11. Zonal profiles of the average (top) $v^{\prime}$ and (bottom) $\theta^{\prime}$ over the top $1000 \mathrm{~m}$ across the basin, for each of the $24^{\circ}-26^{\circ} \mathrm{N}$ CTD sections. The ensemble mean profiles are shown by bold solid lines.

near the western boundary, and a similar mean value of $\sim 0.1 \mathrm{PW}$ is found. Therefore the mean value of $Q_{\mathrm{EDDY}}=$ $0.10 \mathrm{PW}$ could be taken as a time-invariant estimate along the RAPID line, with a typical temporal uncertainty of 0.03 PW.

Given the observed structure of $Q_{\text {EDDY }}$, it is also possible to form a continuous estimate of it from the mooring array, using a piecewise approach. The ocean is broken into segments between moorings, where $v^{\prime}$ and $\theta^{\prime}$ represent zonally averaged anomalies over each segment, and an integration of these discrete segments across the ocean interior is performed. This approach will not resolve any eddy heat flux that results from true mesoscale covariabilty of $v^{\prime}$ and $\theta^{\prime}$ but can resolve the contribution by the large-scale, quasi-stationary covariance pattern, provided the moorings are located in such a way as to capture it.

Between the eastern and western boundaries, there are three locations where top-to-bottom density profiles can be created and therefore a total of four zonal segments across the ocean interior. An estimate of $Q_{\text {EDDY }}$ can then be made by computing $V^{\prime}$ profiles for each segment relative to the zonal (boundary-to-boundary) mean $V$ profile at each time, and the corresponding $\theta^{\prime}$ profiles relative to the zonal RAPID climatology and summing these $Q_{\text {EDDY }}$ contributions across the section. Almost all of the estimated flux is captured by the westernmost segment, between moorings WB2 and WB5, as could be anticipated from Fig. 9a (mooring WB5 is located about $500 \mathrm{~km}$ from the western boundary). The time series of $Q_{\mathrm{EDDY}}$ derived in this manner is shown in Fig. 8 (light blue line). Its mean value and standard deviation over the 3.5 -yr record is $0.11 \pm 0.04 \mathrm{PW}$, very 
consistent with the mean value estimated from the CTD sections. The corresponding estimate obtained from the CTD sections when they are subsampled to the mooring configuration is $0.10 \pm 0.05 \mathrm{PW}$, the same mean value but a larger variability than the results obtained from the full CTD sections. This agreement indicates that the sparse interior array configuration is sufficient to capture most of the interior eddy heat flux contribution, and that it provides an unbiased estimate of this quantity. We therefore choose to use the array-derived estimate of $Q_{\mathrm{EDDY}}$ in the final MHT estimate. Its range of variation ( $-0.02-0.22 \mathrm{PW}$ over the 3.5 -yr period) is probably somewhat larger that of the actual $Q_{\text {EDDY }}$ variation because it is influenced by individual mesoscale features as they cross from one zonal segment to another, but this variability should average out on time scales larger than a few months. Overall, it seems preferable to have a concurrent estimate of this flux rather than one that relies solely on historical sections, as the magnitude of this term could change (if, for example, the partitioning of the western boundary subtropical gyre return flow between the Florida and Antilles Currents were to vary on interannual or secular time scales). In principle, the MiamiGibraltar XBT section can also be used to keep track of $Q_{\text {EDDY }}$ on a quarterly basis; however, it does not run along exactly the same section and appears to have more variation at the eastern boundary than along $24^{\circ}-26^{\circ} \mathrm{N}$.

The net heat transport across $26.5^{\circ} \mathrm{N}$, after summing all of the above individual contributions, is $1.35 \pm 0.40$ PW (Fig. 8 and Table 1), with a seasonally adjusted mean value of $1.33 \mathrm{PW}$ (see Section 3c). The overall uncertainty of this estimate, including statistical uncertainties as well as possible measurement biases, is discussed in section $3 \mathrm{e}$.

\section{b. MHT and MOC variability}

The computed MHT exhibits a considerable range of variability on both intraseasonal and longer ( $\sim$ annual $)$ time scales. The total range of the MHT is $0.2-2.5 \mathrm{PW}$, an amplitude of variability that is just about the same size as its mean value. This variability arises from variability in all of the terms but primarily from the Ekman, Florida Current, and interior $\left(Q_{\mathrm{MO}}\right)$ fluxes. When calculated relative to $\theta_{\text {midocean }}$, correlations between the individual temperature transports are weak (typically $<|0.1|$ ), except for a significant negative correlation between $Q_{\mathrm{MO}}$ and $Q_{\mathrm{WB}}(r=-0.49)$. If these two are summed together to represent the entire interior Bahamas to Africa temperature transport (excluding $Q_{\mathrm{EDDY}}$ ), the cross correlations between all terms become small. In fact, the correlations are sufficiently weak that the sum of the variances of the individual terms (relative to $\theta_{\text {midocean }}$ ) almost exactly equals the variance of the total heat transport. (Note that

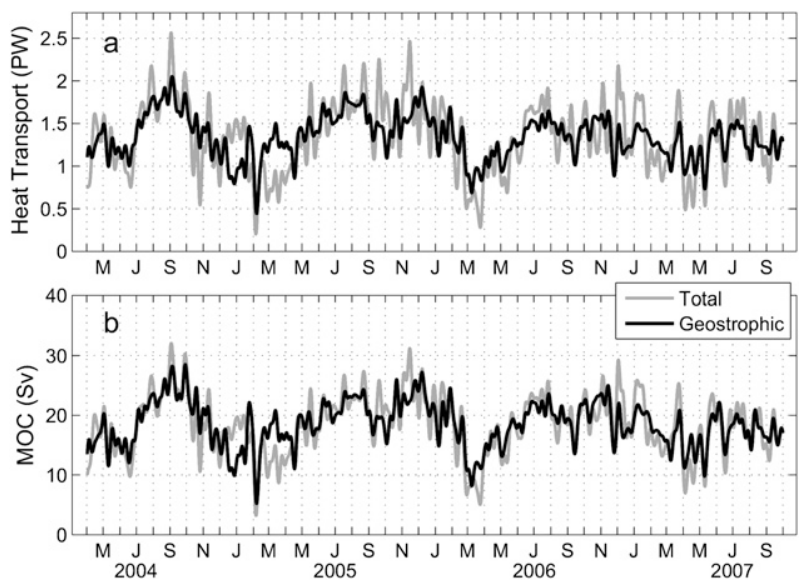

FIG. 12. Time series of (top) meridional heat transport and (bottom) maximum value of the meridional overturning streamfunction. Light lines show the total variability; heavy lines show the variability attributable to the geostrophic circulation, after the direct influence of Ekman transport fluctuations are removed.

this behavior is not prescribed a priori by the way these fluxes are defined, and one can easily think of simple modes of variability where this would not be the case; the same weak correlation between Ekman, Florida Current, and midocean volume transports was noted by Cunningham et al. 2007.) It is therefore possible to make a direct inference of the contribution of variance to the net heat transport by each component. These variance contributions are as follows, in order of decreasing importance: $Q_{\mathrm{EK}}=46 \%, Q_{\mathrm{MO}}=25 \%, Q_{\mathrm{FC}}=20 \%$, $Q_{\mathrm{WB}}=8 \%$, and $Q_{\mathrm{EDDY}}=1 \%$. Thus, the Ekman transport variability accounts for nearly half of the total heat transport variability.

Another way to demonstrate this is to explicitly remove the Ekman transport variability from the MHT calculation, by forcing the Ekman transport to have a constant value that is given by its mean value over the whole period (3.5 Sv). The interior mass compensation is then recalculated by forcing the total interior transport to balance just the sum of the Florida Current and wedge transports and the mean Ekman transport, and the MHT is recomputed. The resulting MHT time series is shown in Fig. 12a, where it is superimposed on the total MHT variability. This can be taken to represent the MHT variability associated with the geostrophic circulation, in the absence of any Ekman transport variability. The standard deviation of this series is $0.24 \mathrm{PW}$, compared to the full MHT standard deviation of 0.40 PW. Much of this reduction is associated with suppression of shortterm variations, while the low-frequency character of the record remains essentially the same.

The same approach can be applied to produce an estimate of the MOC variability with the influence of Ekman 


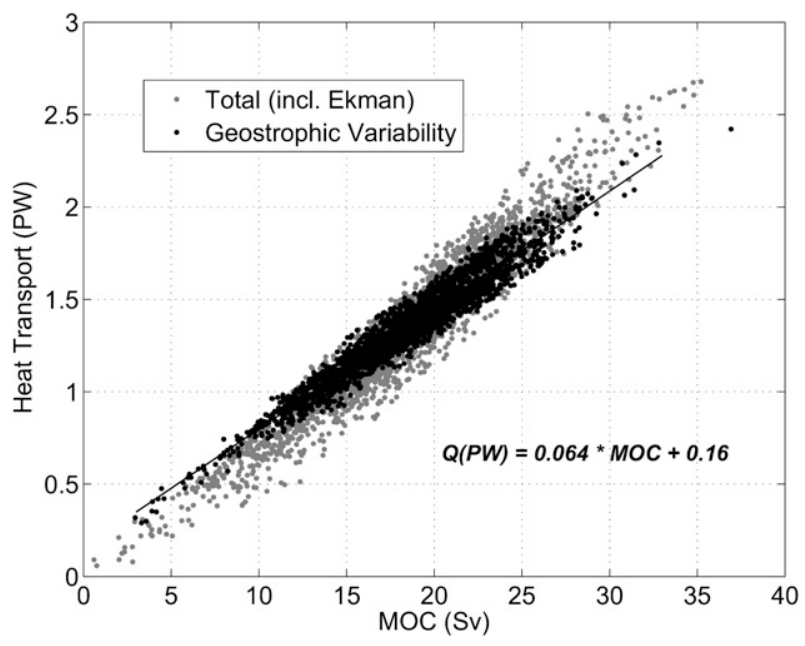

FIG. 13. Linear relationship between the meridional heat transport and maximum MOC value (from time series of Fig. 12), showing results with Ekman variability included (light dots), and excluded (heavy dots). The linear regression for the geostrophic variability is indicated; $r^{2}$ values are 0.94 for both regressions. The linear regression for the total heat transport and MOC variability (light dots) is $Q(\mathrm{PW})=0.079 \mathrm{MOC}-0.12$.

fluctuations removed (Fig. 12b). Here, the same effect can be seen on the high-frequency variability, although the impact is more pronounced on the MHT since the sensitivity of the MHT to the Ekman transport is magnified by the large temperature difference between the Ekman layer and the ocean interior.

Both the MHT and MOC time series show an apparent seasonal cycle, which is more evident in the early part of the record than in the latter part. It is also clear from Fig. 12a that much of this seasonal variability is contained in the geostrophic component of the circulation. We describe the seasonal cycle in more detail in section $3 \mathrm{c}$.

Also evident in Fig. 12 is the high degree of correlation between the MHT and the MOC. This correlation is quantified in Fig. 13, where the regression between the MHT and MOC is shown for both the total variability and the geostrophic variability. The $r^{2}$ value is approximately 0.94 for both regressions and yields the relation $Q=0.064 \mathrm{MOC}+$ $0.16 \mathrm{PW}$, for the geostrophic variability. We focus on this relationship because it should be more representative of the change in MHT that would accompany a large-scale change in the overturning circulation unrelated to local Ekman forcing. The sensitivity of the MHT to a change in the strength of the MOC is thus about $0.06 \mathrm{PW}$ per sverdrup of MOC variation.

\section{c. The seasonal cycle of the MHT}

The total MHT shown in Fig. 8 exhibits a seasonal cycle with a tendency for maxima in heat transport in boreal summer and fall (June-November) and minima

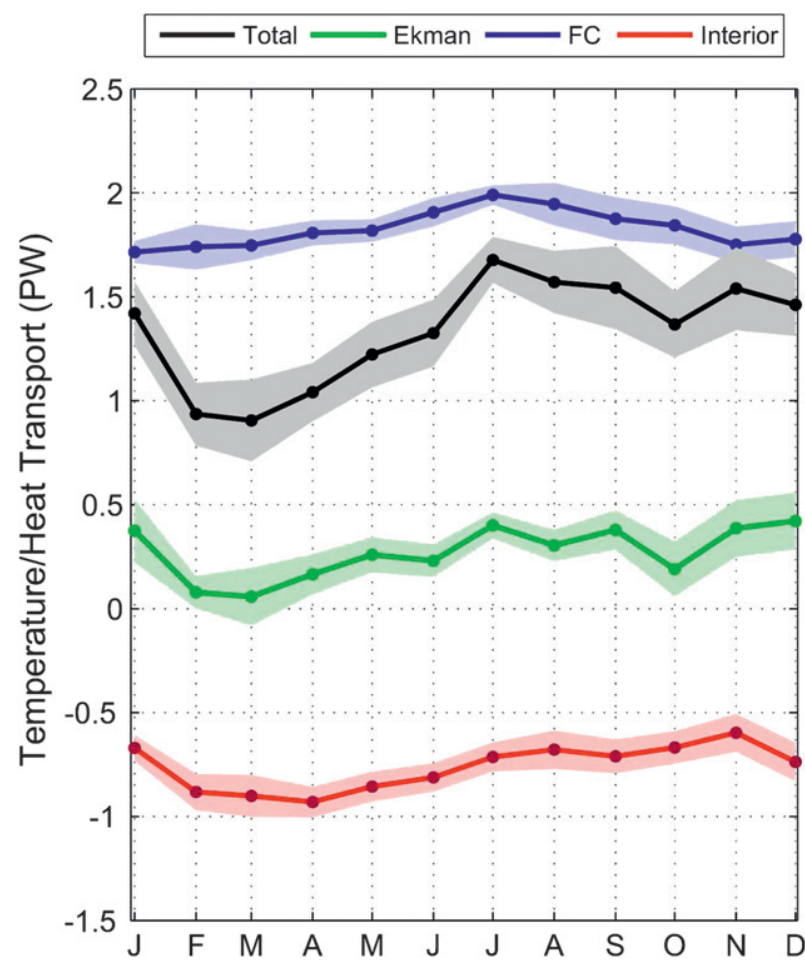

FIG. 14. Monthly climatology of terms comprising the total meridional heat transport, for the "mass-neutral" fluxes calculated relative to the interior ocean mean temperature $\left(\theta_{\text {midocean }}=\right.$ $\left.5.33^{\circ} \mathrm{C}\right)$. The interior contribution shown here, $Q_{\mathrm{INT}}=Q_{\mathrm{MO}}+$ $Q_{\mathrm{WB}}+Q_{\mathrm{EDDY}}$, represents the sum of all the interior ocean (Bahamas-Africa) contributions. Shading around each curve represents the \pm standard error of each monthly estimate.

in spring (February-April). This seasonal variation appears to be quite robust over the first $2 \mathrm{yr}$ but is considerably weaker in the last $1.5 \mathrm{yr}$. Caution is therefore in order when drawing conclusions about a seasonal cycle from the record available to this point. The same variation is present in the MOC record, which as shown above is the primary driver of the MHT variability.

To better quantify this seasonal cycle we show in Fig. 14, a composite monthly climatology of the MHT is derived from the 3.5-yr record. This is generated by simply sorting the data according to the month of observation and averaging together all data from the same month. The seasonal sampling is uneven, with observations from 4 separate years for the months from April to September and 3 yr for the months from October to March. Standard deviations for the monthly estimates assume each month from separate years is independent.

The MHT seasonal cycle estimated in this way shows a distinct minimum $(\sim 0.9 \mathrm{PW})$ in March and a broad maximum in summer and fall, with the largest value $(\sim 1.6 \mathrm{PW})$ in July. According to the error bars this cycle is significant at a $1 \sigma$ level $(67 \%)$, where the months from 
February to April are distinct from the months between July and December. At the $2 \sigma$ level $(95 \%)$ only the February-March and July-August values remain statistically distinct. The amplitude of the seasonal cycle is approximately $0.3 \mathrm{PW}$ with a total annual range of nearly $0.7 \mathrm{PW}$ or about half the magnitude of the mean MHT. From these monthly values we can also compute a "deseasonalized" estimate of the mean MHT, to remove the effect of uneven sampling in different parts of the year, and this value is $1.33 \mathrm{PW}$, hardly different from the temporal mean of $1.35 \mathrm{PW}$ for the series.

A seasonal climatology is constructed in the same manner as above for the main components of the temperature transport (Fig. 14), where the $Q_{\mathrm{MO}}, Q_{\mathrm{WB}}$, and $Q_{\text {EDDY }}$ components are combined together into a single term $Q_{\mathrm{INT}}$, representing the total temperature transport for the interior ocean between the Bahamas and Africa.

Each of these contributions has some seasonal variability, and they sum together such that the seasonal variability of the total MHT is greater than that for any individual component. The main character of the seasonal cycle derives from the Ekman and interior contributions, which have similar seasonal cycles with minima in late winter or early spring (February-March for $Q_{\mathrm{EK}}$, and April for $Q_{\mathrm{INT}}$ ) and broad maxima in summer and fall. The Florida Current seasonal cycle has a maximum in summer that contributes to the absolute maximum of the total MHT in July.

The seasonal cycles of $Q_{\mathrm{FC}}$ and $Q_{\mathrm{EK}}$ are determined primarily by the variability of the corresponding Florida Current transport and basinwide Ekman transport. The Florida Current transport cycle derived from the 3.5-yr record has an annual range of $2.9 \mathrm{~Sv}$, which is typical of the annual variation derived from previous studies (Schott et al. 1988; Molinari et al. 1985) and from the 26-yr-long available cable record (Meinen et al. 2010; Kanzow et al. 2010; Atkinson et al. 2010). The characteristic summer transport maximum and fall transport minimum have been linked to local and regional wind stress forcing in the western North Atlantic and Caribbean Sea (Schott et al. 1988) and are decoupled from wind stress curl (Sverdrup) forcing across the ocean interior (Anderson and Corry 1985; Hogg and Johns 1995). Therefore, the seasonal cycle of $Q_{\mathrm{FC}}$ in Fig. 14 appears to be representative. The Ekman transport cycle derived from the 3.5-yr record, however, shows significant differences from climatology (Kanzow et al. 2010). The late winter minimum in Ekman transport is not reflected in the average seasonal cycle of the National Centers for Environmental Prediction (NCEP) reanalysis from 1982 to the present (Atkinson et al. 2010) and arises due to an unusually strong southward Ekman transport anomaly that occurred in March 2005. If the climatological Ekman transport were to be used instead, the February-March $Q_{\text {EK }}$ values would be higher by about $0.15 \mathrm{PW}$, and the annual range of the net MHT cycle would be reduced to about 0.5 PW from $0.7 \mathrm{PW}$.

The seasonal variation of $Q_{\text {INT }}$ is robust and can be attributed mainly to an intensification of the southward upper-ocean mass transport within the ocean interior in late winter and a reduction in summer and fall. Kanzow et al. (2010) show that this occurs primarily due to annual shoaling and deepening of the thermocline near the eastern boundary, producing a corresponding change in the basinwide vertical shear, with maximum shear and upper-ocean transport in winter and minimum shear and transport in summer/fall. Unlike the Florida Current and Ekman transports, we have no climatological estimate of this transport from a longer time series. However, physical support for this seasonal cycle is given by Kanzow et al. (2010), who show that a simple, forced Rossby wave model using QuikSCAT winds produces a seasonal cycle of the interior upper-ocean transport very similar to that observed. The associated amplitude of the upper-ocean transport variation is $3 \mathrm{~Sv}$. The main forcing responsible for this cycle is the large annually reversing wind stress curl anomaly near the eastern boundary, related to annual variability of the meridional winds off the North African coast (Chidichimo et al. 2010).

An important conclusion to be drawn from these results is that much of the seasonal variation of the MHT at $26.5^{\circ} \mathrm{N}$ is due to variations in the geostrophic circulation; that is, it is not dominated simply by Ekman heat transport variability as has frequently been implied by modeling studies (Böning et al. 2001; Jayne and Marotzke 2001). If we take our $Q_{\text {INT }}$ cycle to be representative of the climatological seasonal cycle (albeit requiring more years of observation to determine with confidence) and assume that our $Q_{\mathrm{EK}}$ seasonal cycle is overestimated, as described above, then the dominant contribution to the seasonal MHT cycle comes from the interior geostrophic circulation and to a lesser extent from the Florida Current.

\section{d. Overturning and gyre heat transport}

The total heat transport can be partitioned into "overturning" and "gyre" heat transport components (Bryan 1982; Böning and Herrmann 1994), defined by

$$
\begin{aligned}
Q_{\mathrm{OT}} & =\int \rho c_{p}\langle V\rangle\langle\theta\rangle d z \text { and } \\
Q_{\mathrm{GYRE}} & =\iint \rho c_{p} v^{*} \theta^{*} d x d z,
\end{aligned}
$$

where angle brackets now represent the zonal average across the entire transoceanic section (from Florida to 
Africa), asterisks represent the deviations from these zonal means, and $V$ is the transport per unit depth profile as previously defined. Here, $Q_{\text {Oт }}$ represents the heat transport associated with the basinwide overturning circulation, and $Q_{\mathrm{GYRE}}$ represents the heat transport associated with the residual horizontal circulation. Though referred to as the gyre heat transport, $Q_{\mathrm{GYRE}}$ will also contain any contribution by mesoscale spatial anomalies and therefore is not strictly related to the gyre-scale circulation. It is equivalent to the $Q_{\text {EDDY }}$ defined for the interior circulation alone (which, in fact, was shown to be primarily related to a gyre-scale pattern), but we reserve the term $Q_{\mathrm{GYRE}}$ for the net contribution by this term across the entire transoceanic section. Both $Q_{\mathrm{OT}}$ and $Q_{\mathrm{GYRE}}$ are independent of temperature reference.

The basinwide transport profile $\langle V\rangle$ at any time is given by the sum of its components:

$$
\langle V\rangle(z)=\sum V_{i}(z)=V_{\mathrm{FC}}+V_{\mathrm{EK}}+V_{\mathrm{WB}}+V_{\mathrm{MO}}
$$

where $V_{\mathrm{FC}}, V_{\mathrm{EK}}, V_{\mathrm{WB}}$, and $V_{\mathrm{MO}}$ represent the respective transport profiles for the Florida Current, Ekman layer, western boundary wedge, and midocean region. The transport profile $V_{\mathrm{WB}}$ and $V_{\mathrm{MO}}$ are readily calculated from the measurement array, and for $V_{\mathrm{EK}}$ the Ekman transport is assumed to be distributed uniformly over the top $100 \mathrm{~m}$. The transport profile $V_{\mathrm{FC}}$ is not measured but is found to be highly predictable based on the cable transport itself. Analysis of the available historical direct velocity sections across the Florida Current shows that $87 \%$ of the Florida Current transport profile variance is explained by a first EOF that has a nearly linear, surface-intensified structure, and which is highly correlated with the total transport (Kanzow et al. 2010). Therefore, $V_{\mathrm{FC}}$ is estimated by projecting this EOF onto the instantaneous cable transport. This same method is used in estimating the basinwide MOC profile (Kanzow et al. 2010).

The basinwide mean $\langle\theta\rangle$ profile is obtained by combining the previously calculated interior $\langle\theta\rangle$ profile with climatological $\langle\theta\rangle$ profiles from the western boundary wedge and Florida Current regions, weighted according to their portion of the cross section. The resulting $\langle\theta\rangle(z)$ profile is nearly indistinguishable from the interior $\langle\theta\rangle(z)$ profile because the interior region accounts for more than $98 \%$ of the total cross-sectional area. Combining $\langle V\rangle(z)$ with $\langle\theta\rangle(z)$ and integrating vertically yields a mean value of $Q_{\mathrm{OT}}=1.19 \pm 0.37 \mathrm{PW}$ for the 3.5-yr record, which accounts for $88 \%$ of the total MHT (Table 3). The seasonal variation of $Q_{\mathrm{OT}}$ is shown in Fig. 15.

The remaining $12 \%$ of the heat transport is due to the gyre component $Q_{\mathrm{GYRE}}$, which has a mean value of

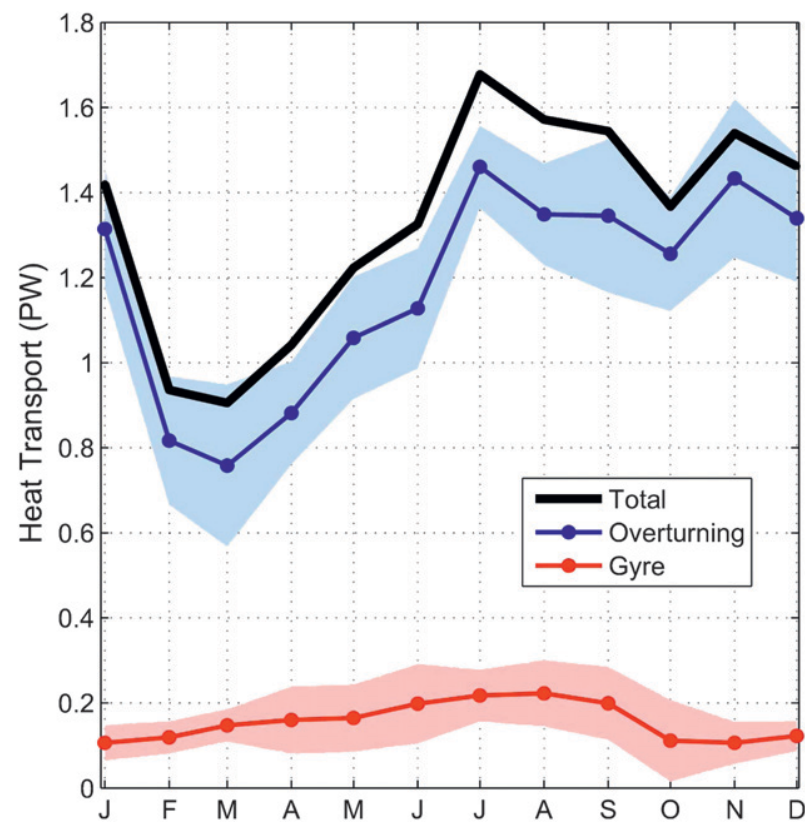

FIG. 15. Monthly climatology of the overturning heat transport $\left(Q_{\mathrm{OT}}\right)$ and "gyre" (nonoverturning) heat transport $\left(Q_{\mathrm{GYRE}}\right)$, derived from the 3.5-yr dataset. The total heat transport is shown by the black line (repeated from Fig. 14). Shading represents \pm 1 standard error of the monthly estimates.

$0.16 \pm 0.07 \mathrm{PW}$, and whose seasonal variation is also shown in Fig. 15. The majority of this is accounted for by the interior $Q_{\text {EDDY }}$ contribution of $0.11 \pm 0.04 \mathrm{PW}$ as previously calculated [it differs negligibly when calculated using the basinwide mean $\langle\theta\rangle(z)$ instead of the interior mean $\langle\theta\rangle(z)$ ]. The remaining contribution comes from the western boundary wedge and Florida Current. The wedge contribution can be directly calculated from the data, and the contribution by the Florida Current may be written alternately as

$$
Q_{\mathrm{GYRE}}^{\mathrm{FC}}=\int \rho c_{p} V_{\mathrm{FC}}^{*} \theta_{\mathrm{FW}}^{*} d z,
$$

where $V_{\mathrm{FC}}^{*}(z)=V_{\mathrm{FC}}(z)-\langle V\rangle(z), \theta^{*} \mathrm{FW}(z)=\theta_{\mathrm{FW}}(z)-$ $\langle\theta\rangle(z)$, and $\theta_{\mathrm{FW}}(z)$ is the seasonally varying flowweighted temperature profile of the Florida Current, calculated from the available Florida Current sections in a manner analogous to that for the bulk $\theta_{\mathrm{FW}}$ shown in Fig. 6. Nearly all of the seasonal signal in $\theta_{\mathrm{FW}}$ comes from the top $150 \mathrm{~m}$ of the Florida Current, with negligible variation below that depth (not shown). Together the Florida Current and western boundary wedge contribute only $0.05 \mathrm{PW}$ to $Q_{\mathrm{GYRE}}$, with a contribution from the Florida Current of $0.03 \pm 0.05 \mathrm{PW}$ and from the western boundary wedge of $0.02 \pm 0.01 \mathrm{PW}$. The positive contribution from the western boundary wedge is 
TABLE 2. Contributions to the total meridional heat transport $\left(Q_{\mathrm{NET}}\right)$ by the overturning $\left(Q_{\mathrm{OT}}\right)$ and gyre $\left(Q_{\mathrm{GYRE}}\right)$ circulations, and the respective contributions to $Q_{\mathrm{GYRE}}$ by the Florida Current, western boundary wedge, and midocean regions. Mean values and standard deviations for both the record-mean (3.5-yr time series) and annual mean (seasonally adjusted) are shown.

\begin{tabular}{lccr}
\hline \multicolumn{1}{c}{ Heat Transport } & Record-mean value & Seasonally adjusted value & Percent of $Q_{\text {NET }}$ \\
\hline$Q_{\text {NET }}$ & $1.35 \pm 0.40$ & $1.33 \pm 0.40$ & - \\
$Q_{\text {OT }}$ & $1.19 \pm 0.37$ & $1.18 \pm 0.37$ & $88 \%$ \\
$Q_{\text {GYRE }}$ (Florida Current) & $0.16 \pm 0.07$ & $0.15 \pm 0.07$ & $12 \%$ \\
$Q_{\text {GYRE }}$ (WB Abaco) & $0.03 \pm 0.05$ & $0.03 \pm 0.05$ & $2 \%$ \\
$Q_{\text {GYRE }}$ (Midocean) & $0.02 \pm 0.01$ & $0.01 \pm 0.01$ & $2 \%$ \\
$Q_{\text {GYRE }}$ & $0.11 \pm 0.04$ & $0.11 \pm 0.04$ & $8 \%$ \\
\hline
\end{tabular}

due to the relatively warmer temperatures (relative to the zonal mean) and positive meridional flow anomaly in the upper ocean associated with the Antilles Current, which essentially amounts to a further western boundary contribution to the gyre-scale pattern shown in Fig. 11. The relatively small contribution by the Florida Current seems at first surprising since the $V_{\mathrm{FC}}^{*}$ anomaly profile here is strongly positive with respect to the zonal mean flow. However, due to the uplift of density (and temperature) surfaces toward the Florida coast associated with the vertically sheared northward flow of the Florida Current (e.g., see Fig. 5), the temperature anomaly of the Florida Current with respect to the zonal mean is positive (warmer) only in the top $\sim 150 \mathrm{~m}$ of the water column and negative (colder, by up to $4^{\circ} \mathrm{C}$ ) in the deeper part of the current. This has been previously noted by Bryden (1993) and Hall and Bryden (1982). The net result is that the Florida Current contribution to $Q_{\mathrm{GYRE}}$ is positive but only weakly so.

The seasonal cycles of $Q_{\mathrm{OT}}$ and $Q_{\mathrm{GYRE}}$ (Fig. 15), calculated in the same manner as described previously, show that most of the seasonal variability of $Q_{\mathrm{NET}}$ is contained in $Q_{\mathrm{OT}}$, associated with the seasonal variation in the strength of the meridional overturning circulation (Fig. 12). A smaller part of this seasonal signal is associated with $Q_{\mathrm{GYRE}}$, which has its maximum in summer and its minimum in fall. Most of the $Q_{\mathrm{GYRE}}$ variation arises from the Florida Current, which has maximum transport in summer coupled with higher flow-weighted temperatures, both of which are concentrated in the upper part of the current. The amplitude of the seasonal $Q_{\mathrm{GYRE}}$ cycle is $0.05 \mathrm{PW}$ and only marginally significant within the statistical uncertainty of the monthly values. The seasonal amplitude of $Q_{\mathrm{OT}}$ is $0.3 \mathrm{PW}$, statistically significant and essentially the same as the seasonal variation of $Q_{\text {NET }}$.

\section{e. The mean MHT and its uncertainty}

To remove any possible seasonal bias in the MHT estimate, a mean value is recomputed from the composite seasonal cycle derived from our 3.5-yr record (Fig. 14), with equal weight placed on each month. This value is $1.33 \mathrm{PW}$, which we take as our best estimate of the annual mean MHT over the period (Table 2).

Uncertainty in the mean heat transport estimate comes from two sources: 1) measurement uncertainty in the MHT estimates and 2) statistical uncertainty related to the MHT fluctuations occurring during the observation period. The measurement uncertainty can further be broken into two parts, a random measurement error and a potential bias error. The main sources of error lie in the transport components measured by the system and these error sensitivities, tested within the computer code used to calculate the MHT, which are as follows:

Florida Current transport: $0.07 \mathrm{PW} / \mathrm{Sv}$,

Ekman transport: $0.08 \mathrm{PW} / \mathrm{Sv}$, and

Mid-ocean transport: $0.05 \mathrm{PW} / \mathrm{Sv}$.

Thus, for example, an error in the Florida Current transport of $1 \mathrm{~Sv}$, when propagated through the calculation, yields an error for the associated MHT of $0.07 \mathrm{PW}$. The error estimate for the midocean transport is obtained by assuming the 1-Sv error is distributed linearly over the top $1000 \mathrm{~m}$. (Distributing it over a larger part of the water column reduces the MHT error.) Measurement uncertainty associated with reasonable temperature errors in any of the components is negligible compared to the transport related errors.

To estimate the random measurement uncertainty we assign the following for typical errors in the instantaneous transport components: Florida Current transport, $\pm 1.7 \mathrm{~Sv}$; Ekman transport, $\pm 1.5 \mathrm{~Sv}$; and midocean transport, $\pm 2.5 \mathrm{~Sv}$. The \pm 1.7 -Sv estimate for the Florida Current is the standard deviation of differences between the instantaneous cable-derived transport and measured in situ transports from the ensemble of cable calibration cruises performed since 1982. The Ekman transport uncertainty is based on differences in instantaneous Ekman transport derived from different wind products and is a conservative estimate of the typical uncertainty. The uncertainty in the midocean transport is based on an analysis of the top-to-bottom baroclinic transport error between pairs of dynamic height moorings, taking into 
account both $T-S$ measurement uncertainties and errors in reconstructing continuous dynamic height profiles from the discrete measurement depths on the moorings (Johns et al. 2005; Kanzow et al. 2006). Using these estimates together with the error sensitivities, we obtain associated MHT measurement uncertainties of \pm 0.12 , \pm 0.12 , and $\pm 0.13 \mathrm{PW}$, for the Florida Current, Ekman, and midocean transports, respectively. Combining these randomly, under the assumption they are uncorrelated, yields a net MHT uncertainty of $\pm 0.21 \mathrm{PW}$. This applies to instantaneous estimates of the MHT and will be substantially reduced by statistical averaging over the length of the record.

The error variance associated with this random measurement uncertainty $\left(0.21^{2}=0.05 \mathrm{PW}^{2}\right)$ is about onethird of the actual sample variance of the MHT time series $\left(0.4^{2}=0.16 \mathrm{PW}^{2}\right)$. Therefore, overall statistical uncertainty in the mean MHT estimate is dominated by the intrinsic MHT variability. To estimate the standard error of the mean MHT estimate we divide the MHT standard deviation by $\sqrt{T / 2 \tau_{I}}$, where $T$ is the length of the time series, and $\tau_{I}$ is the integral time scale, calculated from the autocorrelation function of the series (e.g., Emery and Thomson 2001). The integral time scale is approximately 20 days, yielding 1 degree of freedom for every 40 days of observation. The resulting standard error is $\pm 0.07 \mathrm{PW}$, which represents the statistical uncertainty of the mean MHT estimate, neglecting any possible bias errors. The small size of this error is attributable to the long length of the available record despite the significant variability.

To this statistical uncertainty we must add any possible bias errors resulting from the measurement system. Following the same approach as before, we estimate probable bias errors in each of the main transport components and combine these with the calculated error sensitivities. For the Florida Current transport, the bias error is taken to be $0.4 \mathrm{~Sv}$, which represents the possible error that could be made in the mean value of the Florida Current transport over the 3.5-yr record. This is based on the fact that $6-10$ cable calibration cruises per year are performed on average, yielding $\sim 25$ independent calibration points over the 3.5-yr record, each with $\pm 1.7-\mathrm{Sv}$ accuracy, and therefore a possible mean transport bias of $1.7 / \sqrt{ } 25=0.4 \mathrm{~Sv}$. For the Ekman transport, we assume a possible bias error of $15 \%$ of the mean Ekman transport (3.5 Sv), which yields 0.5 Sv. For the midocean transport, we assume a possible bias error over the entire record of $1 \mathrm{~Sv}$ (Kanzow et al. 2010). The resulting MHT bias errors are $0.03,0.04$, and $0.05 \mathrm{PW}$ for the three components. Combining these randomly (since there is no reason to assume these bias errors have the same sign), the total estimated bias error is $0.07 \mathrm{PW}$.
TABLE 3. Recent estimates of Atlantic ocean meridional heat transport near $24^{\circ}-26^{\circ} \mathrm{N}$, with errors.

\begin{tabular}{lc}
\hline \multicolumn{1}{c}{$\begin{array}{c}\text { Recent estimates at } \\
24^{\circ}-26^{\circ} \mathrm{N}\end{array}$} & $\begin{array}{c}\text { Meridional heat transport } \\
(\mathrm{PW})\end{array}$ \\
\hline Molinari et al. (1990) & $1.21 \pm 0.34$ \\
Fillenbaum et al. (1997) & $1.44 \pm 0.33$ \\
Lavin et al. (1998) & $1.27 \pm 0.26$ \\
Trenberth et al. (2001) & 1.1 (NCEP) \\
Ganachaud and Wunsch (2003) & $1.27 \pm 0.15$ \\
Lumpkin and Speer (2007) & $1.24 \pm 0.25$ \\
This study & $1.33 \pm 0.12$ \\
\hline
\end{tabular}

The total uncertainty of the mean MHT estimate is therefore $0.07 \mathrm{PW}+0.07 \mathrm{PW}=0.14 \mathrm{PW}$. In principle the statistical and bias errors could also be combined randomly, since they have arbitrary signs, but we choose to add them. The final mean MHT estimate for the 3.5-yr period of observations is thus $1.33 \pm 0.14 \mathrm{PW}$.

\section{Discussion}

The mean meridional heat transport estimate at $26.5^{\circ} \mathrm{N}$ derived from this data is somewhat higher than most recent estimates near this latitude in the Atlantic (Table 3) but well within the error bars of the estimates when available. The most recent estimates from inverse models (Ganachaud and Wunsch 2003; Lumpkin and Speer 2007), and averages of hydrographic section estimates along $24^{\circ}-26^{\circ} \mathrm{N}$ (Lavin et al. 1998), are within 0.1 PW of the RAPID-MOCHA estimate but still smaller by 0.06 to $0.09 \mathrm{PW}$. A higher MHT value would be expected for the RAPID-MOCHA estimate since our corresponding MOC estimate, at $18.5 \mathrm{~Sv}$, is also somewhat higher than the respective estimates from hydrography of 16-18 Sv (Ganachaud and Wunsch 2000; Lumpkin and Speer 2007). On the other hand, Trenberth et al.'s (2001) estimate of 1.1 PW from the residual atmospheric method (see Bryden and Imawaki 2001) is considerably smaller than the RAPID-MOCHA estimate and outside our lower error bound. The most recent estimate from climatological air-sea flux measurements, derived from the Coordinated Oceanic-Ice Reference Experiments, version 2 (CORE.v2) dataset (Large and Yeager 2009), yields a value near $24^{\circ} \mathrm{N}$ of $1.2 \mathrm{PW}$, just within our observed range of $1.33 \pm 0.14 \mathrm{PW}$.

Perhaps the most important distinction of the present estimate with respect to previous estimates is that our uncertainty is about a factor of two lower, in particular, relative to the available estimates based on in situ ocean data. The exception is the study of Ganachaud and Wunsch (2003), which has a comparable error bar of $\pm 0.15 \mathrm{PW}$. However, based on what the RAPID-MOCHA dataset now shows about interior ocean variability on seasonal 
and shorter time scales, we believe that error bar is optimistic. The impact of interior ocean circulation variability on the overall MHT variability can be assessed in our calculation by holding the Florida Current transport and Ekman transport constant at their 3.5-yr mean values, which simulates the approach normally used when estimating the MHT from one-time sections and inverse models. The resulting MHT has a standard deviation of $0.19 \mathrm{PW}$, which suggests that MHT estimates based on single sections cannot have an uncertainty much less than $0.2 \mathrm{PW}$. The substantially reduced MHT uncertainty of \pm 0.14 PW we are able to achieve results directly from the ability to average out the internal ocean variability through continuous basinwide observations, even after possible measurement biases are taken into account.

Our derived MHT value is based on an assumed zero net transport through the section, whereas there is actually a net transport of $\sim 1.0 \mathrm{~Sv}$ through the basin resulting from the Bering Strait throughflow to the Arctic. To account for this, a small correction is necessary (e.g., Hall and Bryden 1982), in which an equivalent southward heat flux through the section is included that is equal to the Bering Strait transport times the average midocean temperature: $\left(\rho c_{p}\right)(1.0 \mathrm{~Sv})\left(5.33^{\circ} \mathrm{C}\right)=-0.02$ $\mathrm{PW}$, which is negligible. Stated more properly, if we consider the heat budget of the North Atlantic plus Arctic, there is a net heat flux convergence by the ocean circulation of $1.31 \mathrm{PW}$ that is available for heat loss to the atmosphere, made up of $1.33 \mathrm{PW}$ transported northward across $26.5^{\circ} \mathrm{N}$ by the mass-conserving circulation, and a divergence of $0.02 \mathrm{PW}$ due to the difference in temperature of the Bering Strait inflow $\left(\sim 0^{\circ} \mathrm{C}\right)$ and the mean ocean temperature at $26.5^{\circ} \mathrm{N}\left(5.33^{\circ} \mathrm{C}\right)$, at a mean transport of $\sim 1.0 \mathrm{~Sv}$.

The degree of MHT variability revealed by these measurements is, at first glance, surprising. The MHT varies by order one about its mean value, from about 0.2 to $2.5 \mathrm{PW}$, and, even when the Ekman heat transport variability is excluded, the range of variability is still about 2 PW (Fig. 12). As there is no other similar, observationally based MHT time series to compare this result with, the question can be asked: is this behavior consistent with expectations from realistically forced, high-resolution numerical models? Böning et al. (2001), in a model intercomparison study of the North Atlantic, found a range of variability of approximately $2.4 \mathrm{PW}$ for the MHT at $25^{\circ} \mathrm{N}$ in a $1 / 3^{\circ}$ resolution model forced with daily European Centre for Medium-Range Weather Forecasts (ECMWF) winds and surface fluxes and a corresponding range of MOC variability of $25 \mathrm{~Sv}$, similar to the observed variability. Hakkinen (1999), using a coarser resolution $\left(0.7^{\circ}\right)$, coupled ocean-ice model forced with monthly the Comprehensive Ocean-Atmosphere
Data Set (COADS) surface forcing, found a smaller range of MHT variability of approximately $0.8 \mathrm{PW}$ relative to a 3-yr running mean and associated MOC variability of $8 \mathrm{~Sv}$. The lower MHT and MOC variability in this simulation presumably results from its lack of synoptic forcing and noneddy-permitting resolution.

More recent studies with higher-resolution models have focused more on the MOC variability than MHT variability but show similar results to that of Böning et al. (2001). Hirschi et al. (2007) found MOC variations of $5-23 \mathrm{~Sv}$ at $25^{\circ} \mathrm{N}$ in a synoptically forced, $1 / 4^{\circ}$ resolution Ocean Circulation and Climate Advanced Model (OCCAM), and Cunningham and Marsh (2010) found variations from $2-26 \mathrm{~Sv}$ in a $1 / 12^{\circ}$ OCCAM model. Thus, the degree of MOC and MHT variability observed in the RAPID-MOCHA array appears to be consistent with results from realistically forced, eddy-resolving (or eddypermitting) models, and confirms that the high range of variability found in these models does, in fact, occur in the real ocean. Certainly a significant part of this variability is due to simple Ekman-forced changes of the MOC/ MHT, but the observations clearly show that there is considerable variability contained in geostrophic circulation as well. The degree to which this non-Ekman part of the variability is related to external forcing (e.g., winddriven baroclinic variability, Rossby waves) versus unforced internal variability (e.g., mesoscale eddies) remains a subject of continuing study.

An important result from this observational program is that the seasonal cycle of the MHT (and MOC) at this latitude is largely related to seasonal changes in the internal baroclinic structure of the ocean and particularly that in the interior ocean domain between the Bahamas and Africa. As discussed earlier, and shown in Kanzow et al. (2010), the mechanism of this internal variability appears to be the annually reversing wind stress curl anomaly near the eastern boundary. This leads to vertical displacement of the thermocline in the east and a corresponding seasonal cycle in the basinwide, boundaryto-boundary vertical shear across the interior. This explanation differs fundamentally from the conclusions derived from a number of model studies (Bryan 1982; Böning and Herrmann 1994; Jayne and Marotzke 2001; Böning et al. 2001) that the primary mechanism of MOC and MHT variability in midlatitudes on seasonal and shorter time scales is a simple Ekman-forced response, in which the surface Ekman transport is compensated by a nearly instantaneous, vertically uniform (barotropic) flow in the interior. Jayne and Marotzke (2001) note, however, that the rms MHT variability that is unrelated to the Ekman mechanism is about $0.2 \mathrm{PW}$ away from the equator in the Atlantic, which is actually quite similar to our observed rms variability when the direct Ekman influence 
is removed. They further note that the geostrophic (nonEkman) contribution to the MHT variability may be relatively more important near nodes in the mean wind stress pattern, where the wind stress forcing, and related Ekman variability, is less dominant (of which $26^{\circ} \mathrm{N}$ is such a case, being near the wind minimum between the westerlies and NE trades). The apparent discrepancy between the model-based and observational results may thus be rationalized in part by $26^{\circ} \mathrm{N}$ being a particular location where the dominance of Ekman forcing of the MHT variability does not hold, although these prior model-based conclusions have certainly held a lasting impression. Further support for the role of internal baroclinic changes in the MOC and MHT variability at $24^{\circ}-26^{\circ} \mathrm{N}$ is found in the recent model study of Hirschi et al. (2007). They computed the contributions to the overall MOC variabilility by Ekman-forcing and basinwide geostrophic shear in various frequency bands and showed that the two contributions are nearly equal on intraseasonal time scales, but that the shear contribution is dominant on seasonal and longer time scales.

A consequence of this internal geostrophic variability on seasonal time scales is that estimates of the strength of the MOC at $26^{\circ} \mathrm{N}$, and associated MHT, based on single hydrographic sections taken at different times of the year may be significantly aliased by this seasonal cycle. Indeed, Kanzow et al. (2010) show that the apparent trend in the MOC strength found by Bryden et al. (2005) largely disappears when the individual hydrographic sections are corrected according to the climatological interior cycle seen in the RAPID-MOCHA observations. Large seasonal changes in the interior ocean baroclinic heat transport from the available $24^{\circ}-$ $26^{\circ} \mathrm{N}$ sections were also noted by Baringer and Molinari (1999), whose seasonal amplitude (0.3 PW) and phase (maximum in summer, minimum in winter) is in agreement with the RAPID-MOCHA observations.

The observed high correlation between the MOC and MHT variability, and the dominance of the overturning heat transport in the seasonal heat transport cycle, indicates that gyre variability is of secondary importance to the MHT variability at this latitude. An important quantity we are able to estimate from this program is the sensitivity of the MHT to MOC changes, which is approximately $0.065 \mathrm{PW} / \mathrm{Sv}$ for the non-Ekman-related MOC variability, for the time scales of variability sampled in this program. This should be a valuable metric for comparison with ocean GCMs and coupled models. Another useful metric is the ratio of the mean MHT to the mean MOC strength, which, from our observations, is $1.33 \mathrm{PW} / 18.5 \mathrm{~Sv}=0.072 \mathrm{PW} / \mathrm{Sv}$. Obviously, it is important that models, especially coupled climate models, are able to simulate not only the proper strength of the
MOC but the associated MHT carried by it since this is the primary feedback mechanism to the climate system. There has been a general tendency in forced OGCMs to underestimate the MHT at $\sim 25^{\circ} \mathrm{N}$ in the Atlantic, even when they have a mean MOC strength comparable to observations. For example, Biastoch et al. (2008) examined the relationship between the mean MHT and MOC strength in several published, high-resolution OGCMs, and found, for a set of models with realistic MOC strengths of 16.8 to $19.1 \mathrm{~Sv}$ at $25^{\circ} \mathrm{N}$, corresponding mean MHT values of 0.95 to $1.14 \mathrm{PW}$. The mean MHTMOC ratio in these experiments is fairly consistent at $\sim 0.06 \mathrm{PW} / \mathrm{Sv}$, meaning that the typical model heat transport for an 18.5 Sv MOC is $1.1 \mathrm{PW}$ or abut $0.2 \mathrm{PW}$ less than observed. One possible reason for this is that most OGCMs, especially $z$-coordinate models, tend to have a too shallow southward return flow of North Atlantic Deep Water through the basin, as recently noted by Saunders et al. (2008). Thus, the temperature of this return flow may be too warm and result in too low a MHT value since the heat transport carried by the MOC is proportional to the temperature difference between the northward (upper) and southward (deep) limbs of the cell. Another possibility is that the gyre component of the MHT is not properly represented in some models. For example, Böning et al.'s (2001) study found a nearzero mean contribution of the gyre component of the heat transport $\left(Q_{\mathrm{GYRE}}\right)$, whereas the observed value from the RAPID-MOCHA array is $0.16 \mathrm{PW}$, the same order as the typical model discrepancy. Similar comparisons in coupled climate models would be useful to establish their consistency with observations, and, if discrepancies arise, to help diagnose their cause.

Our observations suggest that the eddy component of the heat transport, per se, is weak, and that most of the nonoverturning heat transport is carried by the largescale gyre circulation. This is fortunate and allows the total gyre/eddy heat transport across the ocean interior to be approximated by a discrete set of moorings, provided that they are suitably located. This result is also consistent with model and limited observational results that suggest a minor contribution of the time-mean, rectified heat flux by mesoscale eddies at this latitude in the Atlantic (Jayne and Marotzke 2002; Volkov et al. 2008; Wunsch 1999). Jayne and Marotzke (2002) found that the eddy heat flux due to temporal correlation of $v^{\prime}$ and $\theta^{\prime}$ anomalies is nearly zero at $26^{\circ} \mathrm{N}$, which is located between a region of positive values to the north (up to $\sim 0.1 \mathrm{PW}$ at $40^{\circ} \mathrm{N}$ ) and negative values to the south $\left(-0.2 \mathrm{PW}\right.$ at $\left.15^{\circ} \mathrm{N}\right)$. Stammer's (1998) estimate based on an eddy-diffusive model and altimeter-derived statistics also showed a near-zero $(<0.02 \mathrm{PW})$ eddy heat flux at this latitude. Direct estimates of the local eddy heat flux from 
current-meter records by Wunsch (1999) indicate typical values of $\overline{v^{\prime} \theta^{\prime}}<10^{-2} \mathrm{~m}^{\circ} \mathrm{C} \mathrm{s}^{-1}$ in the subtropical Atlantic and a maximum eddy heat flux $<0.05$ PW. Similarly, Fillenbaum et al. (1997) and Leaman et al. (1987) show eddy heat fluxes of $\leq 0.01 \mathrm{PW}$ for the energetic western boundary regimes off the Bahamas and within the Straits of Florida. Therefore, we conclude that the mesoscale eddy heat flux can be neglected at this latitude.

The fundamental result from this program, to date, is the definition of a multiyear, contemporary mean meridional heat transport and associated MOC strength, at $26.5^{\circ} \mathrm{N}$, and their range of variability. Obviously, the time series is too short to say anything about possible trends or multiyear variability. It is useful to consider what these trends might be, and what will be required of observations to resolve them. The consensus of the IPCC AR4 simulations is that a decrease of approximately $25 \%$ could occur in the Atlantic MOC during the next century. If the MHT-MOC relationship remains stable, then this would result in a decrease in the MHT at $26^{\circ} \mathrm{N}$ of approximately $0.3 \mathrm{PW}$. The stability of this relationship is by no means certain as Drijfhout and Hazeleger (2006) found in an ensemble of coupled climate simulations with greenhouse gas forcing that a reduction in the heat transport carried by the MOC was approximately balanced by an equal increase in the gyre component of heat transport. Simply measuring the MOC may therefore be inadequate to capture the climate significance of a long-term MOC change. On interannualto-decadal time scales, models suggest that significant changes in the MHT can occur in connection with largescale atmospheric forcing changes, such as those associated with the North Atlantic oscillation (NAO). Eden and Willebrand (2001) found changes in the MHT of up to $0.2 \mathrm{PW}$ in the subpolar North Atlantic associated with $\mathrm{NAO}$ forcing and a lagged response in the subtropics of up to $0.16 \mathrm{PW}$ between low and high NAO states. Thus, for both long-term (anthropogenic) and decadal timescale variability, an ability to resolve multiyear changes in heat transport to an accuracy of about $0.1 \mathrm{PW}$ will be required to document the linkages between these climate variations and the ocean heat transport. The RAPID-MOCHA array is the first observational program capable of providing estimates close to this accuracy. The same level of accuracy will be required of other methods, such as model-based data assimilation techniques, that may be relied on in the future.

\section{Summary}

The observations described herein provide the first continuous time series of meridional heat transport in the global oceans, at a key latitude within the Atlantic basin where the heat transport is close to its maximum. The results should provide a valuable benchmark for testing ocean circulation models, coupled climate models, and indirect methods used for estimating ocean heat transport via residual or surface flux methods. The main conclusions from this study are as follows:

- The average, annual mean meridional heat transport across $26.5^{\circ} \mathrm{N}$ for $2004-07$ is $1.33 \pm 0.14 \mathrm{PW}$. This mean value is slightly higher than most recent estimates from observations, but its uncertainty is substantially smaller, about $\pm 10 \%$ of the mean value instead of the $\pm 20 \%$ typical of previous estimates.

- The short-term variability of the heat transport is large, with a range from 0.2 to $2.5 \mathrm{PW}$ and standard deviation of $0.4 \mathrm{PW}$. About half of this variability can be directly attributed to Ekman transport changes; the remainder is due to geostrophic circulation changes. The range of variability is consistent with eddypermitting or eddy-resolving OGCMs; however, the geostrophic variability appears to play a larger role than previously suggested by models at this latitude.

- A seasonal cycle is evident, with maximum heat transport in boreal summer/fall and minimum in boreal spring, of amplitude 0.3 PW. While both Ekman transport and western boundary (Florida Current) variations contribute to this seasonal cycle, the main contribution is through interior ocean baroclinic changes forced by annual wind stress curl variability in the eastern basin.

- The meridional heat transport is highly correlated with changes in the strength of the meridional overturning circulation. The overturning circulation accounts for nearly $90 \%$ of the total heat transport, and the remaining heat transport, associated with velocity and temperature anomalies relative to their zonal means, is contained in a quasi-stationary gyre pattern, with little net contribution by mesoscale eddies.

The main objective of the RAPID-MOCHA array, as originally conceived, is to provide a means to continuously monitor the basinwide mass transport profile and associated meridional overturning streamfunction. Extending this to heat transport estimates is, for the most part, straightforward but has certain limitations within the present methodology. Among these are the reliance on a midocean hydrographic climatology to determine the interior zonal mean temperature profile, and the use of a piecewise reconstruction of the "gyre" contribution to the total heat transport rather than having a fully resolved interior circulation. A potential future improvement will be to strategically merge Argo interior observations (e.g., Willis 2010) with the endpoint hydrographic boundary constraints provided by the array, to provide more 
complete hydrographic and circulation fields within the interior. At the present time, the RAPID-MOCHA array is planned to be continued until at least 2014, to provide a decade or longer continuous time series, and therefore updates will be forthcoming.

Acknowledgments. This research was supported by the U.S. National Science Foundation under Awards OCE0241438 and OCE0728108, by the U.K. RAPID Programme (RAPID Grant NER/T/S/2002/00481), and by the U.S. National Oceanic and Atmospheric Administration, as part of its Western Boundary Time Series Program. The mooring deployment and recovery operations were skillfully carried out by the University of Miami Ocean Technology Group and the U.K. Natural Environment Research Council mooring group. The authors thank the captains and crews of the RRS Discovery, R/V Knorr, R/V Seward Johnson, and NOAA Ship Ronald H. Brown for their dedication and capable assistance in the mooring cruises and shipboard data acquisition activities.

\section{REFERENCES}

Anderson, D. L. T., and R. A. Corry, 1985: Seasonal transport variations in the Florida Straits-A model study. J. Phys. Oceanogr., 15, 773-786.

Atkinson, C. P., H. L. Bryden, J. J.-M. Hirschi, and T. Kanzow, 2010: On the variability of Florida Straits and wind driven transports at $26^{\circ} \mathrm{N}$ in the Atlantic Ocean. Ocean Sci., 6, 837-859.

Baringer, M. O., and R. Molinari, 1999: Atlantic Ocean baroclinic heat flux at $24^{\circ}$ to $26^{\circ} \mathrm{N}$. Geophys. Res. Lett., 26, 353-356.

— transport at $27^{\circ}$ N. Geophys. Res. Lett., 28, 3179-3182.

Biastoch, A., C. W. Böning, J. Getzlaff, J. M. Molines, and G. Madec, 2008: Causes of interannual-decadal variability in the meridional overturning circulation of the midlatitude North Atlantic Ocean. J. Climate, 21, 6599-6615.

Böning, C. W., and P. Herrmann, 1994: Annual cycle of poleward heat transport in the ocean: Results from high-resolution modeling of the North and equatorial Atlantic. J. Phys. Oceanogr., 24, 91-107.

_ tion in the western subtropical North Atlantic: Experiments with an eddy-resolving model. J. Phys. Oceanogr., 21, 12711289.

— C. Dieterich, B. Barnier, and Y. L. Jia, 2001: Seasonal cycle of meridional heat transport in the subtropical North Atlantic: A model intercomparison in relation to observations near $25^{\circ} \mathrm{N}$. Prog. Oceanogr., 48, 231-253.

Bryan, K., 1982: Seasonal variation in meridional overturning and poleward heat transport in the Atlantic and Pacific Oceans: A model study. J. Mar. Res., 40, 39-53.

Bryden, H. L., 1993: Ocean heat transport across $24^{\circ} \mathrm{N}$ latitude. Interactions Between Global Climate Subsystems, The Legacy of Hann, Geophys. Monogr., Vol. 75, Amer. Geophys. Union, $65-75$.
- and S. Imawaki, 2001: Ocean heat transport. Ocean Circulation and Climate: Observing and Modelling the Global Ocean, G. Siedler et al., Eds., International Geophysics Series, Vol. 77, Academic Press, 455-474.

- H. R. Longworth, and S. A. Cunningham, 2005: Slowing of the Atlantic meridional overturning circulation at $25^{\circ} \mathrm{N}$. $\mathrm{Na}$ ture, 438, 655-657.

Chidichimo, M. P., T. Kanzow, S. A. Cunningham, W. E. Johns, and J. Marotzke, 2010: The contribution of eastern boundary density variations to the Atlantic meridional overturning circulation at $26.5^{\circ}$ N. Ocean Sci., 6, 475-490.

Conkright, M. E., R. A. Locarnini, H. E. Garcia, T. D. O’Brien, T. P. Boyer, C. Stephens, and J. I. Antonov, 2002: World Ocean Atlas 2001: Objective analyses, data statistics and figures CD-ROM documentation. National Oceanographic Data Center Internal Rep. 17, 17 pp.

Cunningham, S. A., and R. Marsh, 2010: Observing and modeling changes in the Atlantic MOC. Wiley Interdisciplinary Reviews: Climate Change, John Wiley \& Sons, 180-191.

_ meridional overturning circulation at $26.5^{\circ} \mathrm{N}$. Science, $\mathbf{3 1 7}$, 935-938.

Curry, R., 1996: HYDROBASE: A database of hydrographic stations and tools for climatological analysis. WHOI Tech. Rep. WHOI-96-01, 50 pp.

Drijfhout, S. S., and W. Hazeleger, 2006: Changes in MOC and gyre-induced Atlantic Ocean heat transport. Geophys. Res. Lett., 33, L07707, doi:10.1029/2006GL025807.

Eden, C., and J. Willebrand, 2001: Mechanism of interannual to decadal variability of the North Atlantic circulation. J. Climate, 14, 2266-2280.

Emery, W. J., and R. E. Thomson, 2001: Data Analysis Methods in Physical Oceanography. Elsevier Science, 638 pp.

Fillenbaum, E. R., T. N. Lee, W. E. Johns, and R. J. Zantopp, 1997: Meridional heat transport variability at $26.5^{\circ} \mathrm{N}$ in the North Atlantic. J. Phys. Oceanogr., 27, 153-174.

Ganachaud, A., and C. Wunsch, 2000: Improved estimates of global ocean circulation, heat transport and mixing from hydrographic data. Nature, 408, 453-457.

$\longrightarrow$, and - 2003: Large-scale ocean heat and freshwater transports during the World Ocean Circulation Experiment. J. Climate, 16, 696-705.

Hakkinen, S., 1999: Variability of the simulated meridional heat transport in the North Atlantic for the period 1951-1993. J. Geophys. Res., 104, 10 991-11 007.

Hall, M. M., and H. L. Bryden, 1982: Direct estimates and mechanisms of ocean heat transport. Deep-Sea Res., 29, 339-359.

Hirschi, J. J. M., P. D. Killworth, and J. R. Blundell, 2007: Subannual, seasonal, and interannual variability of the North Atlantic meridional overturning circulation. J. Phys. Oceanogr., 37, 1246-1265.

Hogg, N. G., and W. E. Johns, 1995: Western boundary currents. Rev. Geophys., 33, 1311-1334.

Jayne, S. R., and J. Marotzke, 2001: The dynamics of ocean heat transport variability. Rev. Geophys., 39, 385-411.

- , and - 2002: The oceanic eddy heat transport. J. Phys. Oceanogr., 32, 3328-3345.

Johns, W. E., T. L. Townsend, D. M. Fratantoni, and W. D. Wilson, 2002: On the Atlantic inflow to the Caribbean Sea. Deep-Sea Res. I, 49, 211-243.

_ ports with dynamic height moorings: An application in the 
Atlantic deep western boundary current at $26^{\circ}$ N. Deep-Sea Res. I, 52, 1542-1567.

—, L. M. Beal, M. O. Baringer, J. R. Molina, S. A. Cunningham, T. Kanzow, and D. Rayner, 2008: Variability of shallow and deep western boundary currents off the Bahamas during 2004-05: Results from the $26^{\circ} \mathrm{N}$ RAPID-MOC array. J. Phys. Oceanogr., 38, 605-623.

Kanzow, T., U. Send, W. Zenk, A. D. Chave, and M. Rhein, 2006: Monitoring the integrated deep meridional flow in the tropical North Atlantic: Long-term performance of a geostrophic array. Deep-Sea Res. I, 53, 528-546.

— ated with the MOC at $26.5^{\circ} \mathrm{N}$ in the Atlantic. Science, 317, 938-941.

_ and Coauthors, 2008: A prototype system of observing the Atlantic meridional overturning circulation-Scientific basis, measurement and risk mitigation strategies, and first results. J. Oper. Oceanogr., 1, 19-28.

_ meridional overturning circulation at $26.5^{\circ} \mathrm{N}$. J. Climate, 23, 5678-5698.

Knight, J. R., R. J. Allan, C. K. Folland, M. Vellinga, and M. E. Mann, 2005: A signature of persistent natural thermohaline circulation cycles in observed climate. Geophys. Res. Lett., 32, L20708, doi:10.1029/2005GL024233.

Large, W. G., and S. G. Yeager, 2009: The global climatology of an interannually varying air-sea flux data set. Climate Dyn., 33, 341-364.

Lavin, A., H. L. Bryden, and G. Parilla, 1998: Meridional transport and heat flux variations in the subtropical North Atlantic. Global Atmos. Ocean Syst., 6, 269-293.

,-- , and,- 2003 : Mechanisms of heat, freshwater, oxygen and nutrient transports and budgets at $24.5^{\circ} \mathrm{N}$ in the subtropical North Atlantic. Deep-Sea Res., 50, 1099-1128.

Leaman, K. D., R. L. Molinari, and P. S. Vertes, 1987: Structure and variability of the Florida Current at $27^{\circ} \mathrm{N}$ : April 1982-July 1984. J. Phys. Oceanogr., 17, 565-583.

Lee, T. N., W. E. Johns, F. Schott, and R. Zantopp, 1990: Western boundary current structure and variability east of Abaco, Bahamas at $26.5^{\circ}$ N. J. Phys. Oceanogr., 20, 446-466.

,,-- R. Zantopp, and E. R. Fillenbaum, 1996: Moored observations of western boundary current variability and thermohaline circulation at $26.5^{\circ} \mathrm{N}$ in the subtropical North Atlantic J. Phys. Oceanogr., 26, 962-963.

Lumpkin, R., and K. Speer, 2007: Global ocean meridional overturning. J. Phys. Oceanogr., 37, 2550-2562.

Meehl, G. A., and Coauthors, 2007: Global climate projections. Climate Change 2007: The Physical Science Basis, S. Solomon et al., Eds., Cambridge University Press, 747-845.
Meinen, C. S., M. O. Baringer, and R. F. Garcia, 2010: Florida Current transport variability: An analysis of annual and longerperiod signals. Deep-Sea Res. I, 57, 835-846.

Molinari, R. L., W. D. Wilson, and K. Leaman, 1985: Volume and heat transports of the Florida Current-April 1982 through August 1983. Science, 227, 295-297.

_ E. Johns, and J. F. Festa, 1990: The annual cycle of meridional heat flux in the Atlantic Ocean at $26.5^{\circ}$ N. J. Phys. Oceanogr., 20, 476-482.

Reynolds, R. W., and T. M. Smith, 1994: Improved global seasurface temperature analyses using optimum interpolation. J. Climate, 7, 929-948.

Roemmich, D., and C. Wunsch, 1985: Two transatlantic sections: Meridional circulation and heat flux in the subtropical North Atlantic Ocean. Deep-Sea Res. I, 32, 619-664.

Saunders, P. M., S. A. Cunningham, B. A. de Cuevas, and A. C. Coward, 2008: Comments on "Decadal changes in the North Atlantic and Pacific meridional overturning circulation and heat flux." J. Phys. Oceanogr., 38, 2104-2107.

Schmittner, A., M. Latif, and B. Schneider, 2005: Model projections of the North Atlantic thermohaline circulation for the 21st century assessed by observations. Geophys. Res. Lett., 32, L23710, doi:10.1029/2005GL024368.

Schott, F. A., T. N. Lee, and R. Zantopp, 1988: Variability of structure and transport of the Florida Current in the period range of days to seasonal. J. Phys. Oceanogr., 18, 12091230 .

Shoosmith, D. R., M. O. Baringer, and W. E. Johns, 2005: A continuous record of Florida Current temperature transport at $27^{\circ}$ N. Geophys. Res. Lett., 32, L23603, doi:10.1029/ 2005GL024075.

Stammer, D., 1998: On eddy characteristics, eddy transports, and mean flow properties. J. Phys. Oceanogr., 28, 727-739.

Trenberth, K. E., J. M. Caron, and D. P. Stepaniak, 2001: The atmospheric energy budget and implications for surface fluxes and ocean heat transports. Climate Dyn., 17, 259-276.

Volkov, D. L., T. Lee, and L.-L. Fu, 2008: Eddy-induced meridional heat transport in the ocean. Geophys. Res. Lett., 35, L20601, doi:10.1029/2008GL035490.

Wijffels, S., E. Firing, and H. Bryden, 1994: Direct observations of the Ekman balance at $10^{\circ} \mathrm{N}$ in the Pacific. J. Phys. Oceanogr., 24, 1666-1679.

Willis, J. K., 2010: Can in situ floats and satellite altimeters detect long-term changes in Atlantic Ocean overturning? Geophys. Res. Lett., 37, L06602, doi:10.1029/2010GL042372.

Wunsch, C., 1999: Where do ocean eddy heat fluxes matter? J. Geophys. Res., 104, 13 235-13 249.

Zhang, R., and T. L. Delworth, 2006: Impact of Atlantic multidecadal oscillations on India/Sahel rainfall and Atlantic hurricanes. Geophys. Res. Lett., 33, L17712, doi:10.1029/2006GL026267. 